\title{
Plasticity of Neuron-Glial Interactions Mediated by Astrocytic EphARs
}

\author{
Michael W. Nestor, ${ }^{1,2}$ Lee-Peng Mok, ${ }^{1}$ Mohan E. Tulapurkar, ${ }^{1}$ and Scott M. Thompson ${ }^{1,2}$ \\ ${ }^{1}$ Department of Physiology and 2 Program in Neuroscience and Membrane Biology Training Program, University of Maryland School of Medicine, \\ Baltimore, Maryland 21201
}

\begin{abstract}
Ephrin (Eph) signaling via Eph receptors affects neuronal structure and function. We report here that exogenous ephrinAs (EphAs) induce outgrowth of filopodial processes from astrocytes within minutes in rat hippocampal slice cultures. Identical effects were induced by release of endogenous ephrinAs by cleavage of their glycosylphosphatidylinositol anchor. Reverse transcription-PCR and immunocytochemistry revealed the expression of multiple EphA receptors (EphARs) in astrocytes. Exogenous and endogenous ephrins did not induce process outgrowth from astrocytes transfected with a kinase-dead EphAR construct, indicating that the critical EphARs were located on glia. Concomitant with these morphological changes, ephrinA reduced the frequency of (S)-3,5-dihydroxyphenylglycineevoked NMDA receptor-mediated inward currents in CA1 pyramidal cells, elicited by release of glutamate from glial cells. The sensitivity of CA1 cell synaptic or extrasynaptic NMDA receptors was unaffected by ephrinA, indicating that this effect was mediated by inhibition of glutamate release from glial cells. Finally, ephrinA application decreased the frequency and increased the duration of spontaneous oscillations of the intracellular $\left[\mathrm{Ca}^{2+}\right]$ in astrocytes. We conclude that ephrinA-EphA signaling is a pluripotent regulator of neuronastrocyte interactions mediating rapid structural and functional plasticity.
\end{abstract}

Key words: astrocyte; ephrin; Eph receptor; plasticity; hippocampus; electrophysiology

\section{Introduction}

Dynamic alterations in the physiological function, protein expression, and morphology of synapses in response to experience and internal neuromodulatory chemical signals are likely to underlie developmental maturation, sexual differentiation, and memory formation. Likewise, dysregulation of synaptic structure and function are likely to contribute to many CNS diseases and mental abnormalities.

Although presynaptic nerve terminals and postsynaptic specializations have received the most attention, there is increasing awareness of the contributions of glial cells, particularly astrocytes, to synaptic function (Haydon, 2001). Many CNS synapses are ensheathed with astrocytic processes (Ventura and Harris, 1999; Newman, 2003), which are thought to limit diffusion of neurotransmitters to adjacent synapses by virtue of their high level of expression of glutamate transporters (Tanaka et al., 1997; Cholet et al., 2002; Huang and Bergles, 2004; Marcaggi and Attwell, 2004). These astrocytic processes respond to neurotrans-

\footnotetext{
Received May 29, 2007; revised Sept. 7, 2007; accepted 0ct. 2, 2007.

This work was supported by National Institutes of Health Grants R01 NS40338 and MH65488 (S.M.T.). We thank Song Hong for providing the primary astrocyte cultures, Dr. Joseph P. Y. Kao for the caged glutamate, Dr. Michelle Stone for help with DNA preparation, Dr. Elena Pasquale (Burnham Institute for Medical Research) for kinase-dead EphA4R plasmids, Dr. Dwight E. Bergles (Johns Hopkins University) for the S100B mice, Chris Lee and Dr. Jessica Mong for help with the PCR, Dr. Xiang Cai for technical support, and Dr. Bradley E. Alger for his comments on this manuscript. Portions of these data were presented to the Society for Neuroscience in 2004.

Correspondence should be addressed to Michael W. Nestor, Department of Physiology, Program in Neuroscience and Membrane Biology Training Program, University of Maryland School of Medicine, 655 West Baltimore Street Baltimore, MD 21201. E-mail: mnest001@umaryland.edu.

D01:10.1523/JNEUROSCI.2442-07.2007

Copyright $\odot 2007$ Society for Neuroscience $\quad 0270-6474 / 07 / 2712817-12 \$ 15.00 / 0$
}

mitters with changes in both membrane potential and intracellular $\mathrm{Ca}^{2+}$ concentration (Perea and Araque, 2005). Astrocytic processes also release neurotransmitter precursors that are taken up by neurons (Hertz and Zielke, 2004), as well as neurotransmitters that elicit electrical responses and intracellular $\mathrm{Ca}^{2+}$ release in neurons (Araque et al., 2001; Fellin et al., 2004). Recent evidence in vivo and in vitro has demonstrated the importance of this anatomical juxtaposition of astrocytes and synapses (Haber et al., 2006; Nishida and Okabe, 2007). Interestingly, astrocytes can vary the extent and complexity of their processes under a variety of conditions, including neuroendocrine cycles (GarciaSegura et al., 1994), development (Mong et al., 1999), or injury (Pekny and Nilsson, 2005). These changes are relatively slow, occurring over many hours to days. The chemical cues that induce these changes in astrocyte morphology are incompletely understood.

The ephrins (Ephs) are important intercellular signaling molecules that have been shown recently to affect postsynaptic neuronal structure (Murai et al., 2003; Nishida and Okabe, 2007). Ephrins are ligands for Eph receptor tyrosine kinases. Ephrins and their receptors are classified into two main families: the ephrinA (EphA) family (ephrinA1-A6), which acts preferentially at EphA receptors (EphARs) (EphA1-A9), and the ephrinB (EphB) family (ephrinB1-B3), which acts preferentially at EphB receptors (EphBRs) (EphB1-B6) (Flanagan and Vanderhaeghen, 1998; Murai et al., 2003). The ephrinAs are attached to the extracellular surface of membranes via a glycosylphosphatidylinositol (GPI) anchor (Yamaguchi and Pasquale, 2004). EphARs are highly expressed in brain, particularly in the hippocampus (Murai et al., 2003). The EphA4R is present on postsynaptic dendritic spines, 
and ephrinA3, a ligand for the EphA4R, is concentrated on astrocytic processes surrounding the synapse (Martone et al., 1997; Murai et al., 2003). Activation of neuronal EphA4Rs induces a retraction and shrinkage of dendritic spines, decreasing dendritic spine density after $\sim 45$ min (Murai et al., 2003; Nishida and Okabe, 2007).

We report here rapid protrusion and retraction of thin, filopodia-like processes (having lengths of 2-5 $\mu \mathrm{m}$ ) from thin branches of enhanced green fluorescent protein (GFP)transfected astrocytes in cultured rat hippocampal brain slices. These small, filopodial-like astrocytic processes are part of the tripartite glial-neuronal interaction at the synapse (Ventura and Harris, 1999; Cholet et al., 2002). This process outgrowth and extension from astrocytes was stimulated rapidly by exogenous and endogenous ephrinA and was dependent on glial EphARs. EphrinA simultaneously inhibited spontaneous intracellular $\mathrm{Ca}^{2+}$ oscillations in glia and release of glutamate from glial cells. We therefore suggest that ephrinA-EphAR signaling is an important regulator of tripartite synaptic structure and function.

\section{Materials and Methods}

Slice culture preparation. Hippocampal slice cultures were prepared from postnatal day 6 (P6) rats or transgenic mice expressing GFP under the control of the promoter for the glial protein S100B (Zuo et al., 2004), using the roller tube technique (Gähwiler et al., 1998) as approved by The University of Maryland, School of Medicine Institutional Animal Care and Use Committee (IACUC). In brief, slices were cut on a tissue chopper at a thickness of $400 \mu \mathrm{m}$, attached to glass coverslips in a chicken plasma clot, placed in sealed test tubes with serum-containing medium, and placed in a slowly rotating roller drum in a dry-air incubator at $36^{\circ} \mathrm{C}$. The culture medium consisted of $25 \%$ horse serum, 25\% HBSS, and 50\% basal medium Eagle. Cultures were allowed to mature for 12-14 d in vitro (DIV) before performing any experiments.

Biolistic transfection. Astrocytes in the cultures were transfected using the biolistic gene gun method (Helios; Bio-Rad, Hercules, CA) (McAllister, 2000). Gold pellets (1.0 $\mu \mathrm{m}$ diameter) were coated with spermidine and then placed in a solution of $25 \mu \mathrm{g} / \mu \mathrm{l}$ plasmid DNA for enhanced GFP. The DNA was then precipitated onto the particles by adding $1 \mathrm{M} \mathrm{CaCl}_{2}$. The coated pellets were attached to the walls of the cartridges with a solution of $3.75 \mathrm{ng}$ polyvinylpyrollidone $/ \mathrm{ml}$ ethanol. To transfect the slice cultures, each slice was placed in a small volume of solution containing $40 \mu \mathrm{M}$ AP-5, $40 \mu \mathrm{M}$ 6,7-dinitroquinoxaline-2,3-dione (DNQX), and $10 \mathrm{~mm} \mathrm{Mg}^{2+}$ to block synaptic transmission and reduce excitotoxicity. Cultures were transfected by shooting at a distance of $2 \mathrm{~cm}$ with a pressure of $200 \mathrm{psi}$ through a nylon mesh $\left(90 \mu \mathrm{m}^{2}\right.$ pore size $)$. After transfection, slices were returned to roller tubes and placed in the incubator for $48-72 \mathrm{~h}$.

Immunocytochemistry. Slice cultures and astrocyte cultures were fixed in $4 \%$ paraformaldehyde for $24 \mathrm{~h}$ at $4^{\circ} \mathrm{C}$, rinsed in $0.1 \mathrm{M} \mathrm{PBS}$, and preincubated for $5-10 \mathrm{~h}$ in a blocking solution containing $0.1 \mathrm{M}$ PBS, $0.4 \%$ Triton X-100, 2\% goat serum, and bovine serum albumin (BSA). Slices were then incubated for $24 \mathrm{~h}$ at $4^{\circ} \mathrm{C}$ in either anti-glial fibrillary acidic protein (GFAP) (monoclonal IgG; Sigma, St. Louis, MO) at 1:400 or polyclonal anti-EphA4 (Zymed Laboratories, San Francisco, CA) (Martone et al., 1997) at $6 \mu \mathrm{M}$ in the preincubation solution. For anti-GFAP, slices were washed and then incubated with biotinylated goat anti-mouse secondary antibody (1:200; $5 \mathrm{~h})$, followed by avidin-conjugated Texas Red (Invitrogen, Carlsbad, CA) (1:200; $6 \mathrm{~min})$. For anti-EphA4, slices were washed and then incubated in Alexa 568-conjugated goat antirabbit secondary (Invitrogen; 1:200, 3-8 h). Slices were then washed overnight at $4^{\circ} \mathrm{C}$ and mounted on standard microscope slides. Treatment of cultures using the identical procedures, but without exposure to a primary antibody, resulted in only low levels of uniform, background staining (data not shown).

Time-lapse microscopy. Forty-eight to $72 \mathrm{~h}$ after transfection, slices were placed in a low volume $(1.5 \mathrm{ml})$ recording chamber filled with standard control saline containing the following (in $\mathrm{mm}$ ): $145 \mathrm{NaCl}, 1$
$\mathrm{NaHCO}_{3}, 10$ HEPES (titrated to $\mathrm{pH} 7.4$ ), $2 \mathrm{CaCl}_{2}, 2 \mathrm{MgCl}_{2}, 1 \mathrm{mg} / \mathrm{L}$ Phenol Red, and the antioxidant Trolox $(0.2 \mathrm{~mm}$, to reduce photo damage). Images were taken every minute for 90 min using a CCD camera (Orca ER; Hamamatsu, Shizuoka, Japan) and a $60 \times$ water-immersion objective (1.0 numerical aperture) on an upright microscope (E600; Nikon, Tokyo, Japan) equipped with rhodamine or fluorescein filter sets. Ephrin constructs were added directly to the chamber, and perfusion was ceased. Images were collected using SimplePCI software (Compix, Sewickley, PA). Image integration times were set to allow the faint fluorescence in thin processes to be adequately captured. This often resulted in saturation of the image of the larger diameter processes from which they arose. Photobleaching was minimized by stopping down the field diaphragm and using short exposure times ( $<0.5 \mathrm{~s}$ per image). In some experiments, the recording chamber was heated to $35-37^{\circ} \mathrm{C}$ with a heated microscope slide (Cell Microcontrols, Norfolk, VA), as determined with a small thermister in the chamber.

Data analysis and statistics. Images were analyzed using SimplePCI software (Compix). For time-lapse images, filopodial processes were traced manually, and the length was computed automatically. Baseline process length was defined as the average length of the process before treatment. Friedman's two-way ANOVA was used to compute the difference of the mean normalized values at each time point from the baseline average for morphological data and for $\left[\mathrm{Ca}^{2+}\right]$ oscillations. Analysis of slow inward current (SIC) interevent intervals was performed for each cell by comparing the cumulative probability distributions before and 50 min after compound application using Kolmogorov-Smirnov test. All values are presented as mean \pm SEM.

Primary mouse hippocampal cocultures. Embryonic day 18 (E18) mice were harvested by cesarean section from anesthetized pregnant females (C57BL/6 strain; Charles River). The animal protocol was as approved by The University of Maryland, School of Medicine Institutional Animal Care and Use Committee. The hippocampus was isolated and dissociated by $10 \%(\mathrm{v} / \mathrm{v})$ trypsin (Invitrogen, Bethesda, MD) digestion and trituration with a fire-polished Pasteur pipette. Cells (106 cells; 1000 cells/ $\mathrm{mm}^{2}$ ) were plated onto $28 \mathrm{~mm}$ coverslips precoated with poly-L-lysine and laminin and placed into $35 \mathrm{~mm}$ tissue culture dishes. The cells were plated in Neurobasal medium supplemented with B27, $200 \mu \mathrm{M}$ glutamine, $100 \mathrm{U} / \mathrm{ml}$ penicillin and streptomycin, and $10 \%$ fetal calf serum (all from Invitrogen) and were maintained in a 5\% $\mathrm{CO}_{2} / 95 \%$ air, humidified atmosphere at $37^{\circ} \mathrm{C}$. A complete medium change was performed $1 \mathrm{~d}$ after plating the cells; $50 \%$ of the medium was changed every $3 \mathrm{~d}$. Cultures were imaged at 7-10 DIV.

Calcium measurements. Primary mixed neuron/glial hippocampal cell cultures from mouse were preincubated with $2 \mu \mathrm{M}$ fluo- 4 AM in normal medium for $30 \mathrm{~min}$. Cells were then stimulated as indicated, and the change in fluo- 4 emission at $505 \mathrm{~nm}$ in response to excitation at $488 \mathrm{~nm}$ was used as a measure of the change in the intracellular $\left[\mathrm{Ca}^{2+}\right]$. Images were captured at the rate of one every $3 \mathrm{~s}$, as described above. The fluorescence changes in specific regions of the cells were tracked by marking small $\left(\sim 20 \mu \mathrm{m}^{2}\right)$ regions of interest over the cell bodies in adjacent astrocytes, and the mean fluorescence value in each region of interest was calculated.

Confocal microscopy. Images were taken on a Zeiss Axioscope 500 using a $40 \times$ water-immersion lens. Excitation of GFP was achieved with an Argon laser at 50\% power using the FITC configuration of Zeiss Axioscope LSM software and emitted light that was passed through a dichroic filter centered at $488 \mathrm{~nm}$. Forty-eight to $72 \mathrm{~h}$ after transfection, the slices were placed in a low volume $(1.5 \mathrm{ml})$ recording chamber filled with standard control saline containing the following (in mM): $145 \mathrm{NaCl}, 3$ $\mathrm{KCl}, 10 \mathrm{HEPES}$ (titrated to $\mathrm{pH} 7.4$ ), $2 \mathrm{CaCl}_{2}, 1 \mathrm{MgCl}_{2}, 10$ glucose, Phenol Red $(1 \mathrm{mg} / \mathrm{L})$, and $0.2 \mathrm{~mm}$ Trolox. Image stacks were obtained through the $\mathrm{Z}$ dimension at an average interval of $0.50 \mu \mathrm{m}$, and a maximal brightness projection was made from $20-30$ images.

Acutely isolated astrocytes. Hippocampal slices were prepared from adult Sprague Dawley rats and cells from stratum (str.) radiatum and lacunosum/moleculare were acutely isolated according to previously published methods (Zhou and Kimelberg, 2001). Slices were incubated for $1 \mathrm{~h}$ in $5 \% \mathrm{CO}_{2} / 95 \%$-bubbled artificial CSF (ACSF) containing the following (in mM): $124 \mathrm{NaCl}, 25 \mathrm{NaHCO}_{3}, 5 \mathrm{~N}, \mathrm{~N}$-Bis(2-hydroxyethyl)- 
2-aminoethanesulfonic acid, 15 glucose, $3 \mathrm{KCl}, 1.3 \mathrm{MgSO}_{4}$, and $2 \mathrm{CaCl}_{2}$. After $1 \mathrm{~h}$, a tissue wedge containing str. radiatum and lacunosum/moleculare of area CA1 was dissected from each slice under a microscope. The dissected tissue was then transferred to $\mathrm{Ca}^{2+}$-free saline containing the following (in mM): $145 \mathrm{NaCl}, 3 \mathrm{KCl}, 10 \mathrm{HEPES}$ (titrated to $\mathrm{pH} 7.4$ ), 1 $\mathrm{MgCl}_{2}, 10$ glucose, Phenol Red ( $\left.1 \mathrm{mg} / \mathrm{L}\right)$, and $5 \% \mathrm{CO}_{2} / 95 \%$ and incubated for $1 \mathrm{~h}$. The dissected tissue was transferred to standard ACSF containing $0.24 \mathrm{mg} / \mathrm{ml}$ cysteine (Sigma) and $24 \mathrm{U} / \mathrm{ml}$ papain (Sigma) and incubated at room temperature for $30 \mathrm{~min}$. Next, the sections were transferred to $\mathrm{Ca}^{2+}$-free saline and incubated for $1 \mathrm{~h}$ to stop the enzymatic action on the tissue. Finally, the tissue was triturated gently under the microscope using fire-polished glass pipettes. The triturated tissue was either harvested for PCR or pipetted onto poly-L-lysine-coated coverslips for immunocytochemistry.

PCR. PCR was performed on both acutely isolated adult rat astrocytes (see Fig. 5A) and primary mouse cortical astrocyte cultures (supplemental Fig. $1 B$, available at www.jneurosci.org as supplemental material). Cortical astrocytes were prepared from C57BL/6 mouse embryos on day 18 or 19 using a modification of a published method (Kofuji and Newman, 2004). In brief, the cerebral cortices were dissected, and cortical cells were mechanically dissociated and then plated onto poly-L-lysinecoated glass coverslips. Subconfluent cultures of GFAP-immunoreactive, flat protoplasmic, type I astrocytes were homogenized after 12 DIV using trizol to induce cell lysis. Total RNA was isolated and dissolved in RNasefree $\mathrm{H}_{2} \mathrm{O}$ and prepared for first-strand cDNA synthesis reactions. The first-strand synthesis was done using a standard kit (Invitrogen). In brief, isolated total RNA was combined with an annealing buffer and heated to $70^{\circ} \mathrm{C}$. After annealing, reverse transcription (RT) and amplification was achieved by combining the total RNA with a buffer, reverse transcriptase, and an RNase inhibitor, as well as random hexamers then heating the mixture. cDNA was then combined with gene-specific primers for each Eph receptor as well as glyceraldehyde-3-phosphate dehydrogenase. Primers were based on the UniGene mouse database using proprietary sequences (SuperArray Bioscience, Frederick, MD) (supplemental Fig. $1 B$, available at www.jneurosci.org as supplemental material). Primers, CDNA, and an RT-PCR master mix containing a fluorescent dye were combined and left in a thermocycler overnight. After the RT-PCRs occurred, each reaction was run on a $2 \%$ agarose gel at $115 \mathrm{~V}$ for $\sim 30 \mathrm{~min}$ using $5 \mu \mathrm{g} / \mathrm{ml}$ ethidium bromide and a $1 \mathrm{~kb}$ ladder. Gels were imaged using a Gel Doc XR System (Bio-Rad).

Immunoprecipitation. Organotypic hippocampal cultures were immersed in extracellular saline (see below) containing either $7.6 \mu \mathrm{g} / \mathrm{ml}$ ephrinA3-Fc, $1 \mathrm{U} / \mathrm{ml}$ phosphatidylinositol-specific phospholipase C (PIPLC) at room temperature, or $1 \mathrm{U} / \mathrm{ml}$ PI-PLC at $37^{\circ} \mathrm{C}$. After incubation for 15-30 $\mathrm{min}$, five cultures/treatment were homogenized in radioimmunoprecipitation assay (RIPA)/protein phosphatase inhibitor (PPI) $/ 1 \%$ sodium deoxycholate (DOC) and incubated on ice for $30 \mathrm{~min}$. RIPA/PPI buffer contained the following (in mM): 50 Tris-Cl, $150 \mathrm{NaCl}$, 1 EDTA, $1 \%$ Triton X-100, $0.2 \% \beta$-mercaptoethanol, and $0.1 \%$ SDS at $\mathrm{pH} 7.5$, with both protease (Sigma-P8340) and phosphatase (SigmaP5726, P2850) inhibitors (1:100). The lysate was cleared, and one volume of RIPA/PPI was added to bring DOC to $0.5 \%$. Polyclonal anti-EphA4R (10 $\mu \mathrm{l})$ (Zymed) was incubated with the lysate at $4^{\circ} \mathrm{C}$ overnight on a rotator. The EphA4R-antibody immunocomplex was precipitated with $50 \mu \mathrm{l}$ of prewashed and equilibrated Protein G Plus/Protein A (Calbiochem, La Jolla, $\mathrm{CA}$ ) agarose beads for $1.5 \mathrm{~h}$ at $4^{\circ} \mathrm{C}$. Finally, the beads were washed three times in RIPA/PPI/0.5\% DOC, and the immunocomplex was eluted by boiling for $5 \mathrm{~min}$ in $2 \times$ Laemli's buffer before loading onto the gel.

Western blot analysis. Samples were loaded into NuPage 4-12\% BisTris gels, run in $1 \times$ NuPage 4-morpholinepropanesulfonic acid/SDS running buffer, and transferred onto polyvinylidene difluororide membrane in $1 \times$ Nupage transfer buffer according to the manufacturer protocol (Invitrogen). The membrane was blocked overnight at $4^{\circ} \mathrm{C}$ with $3 \%$ BSA in buffer containing the following (in $\mathrm{mm}$ ): 10 Tris- $\mathrm{Cl}, \mathrm{pH} 8.0,150$ $\mathrm{NaCl}$, and $0.05 \%$ Tween (TBST) and probed for $1 \mathrm{~h}$ with an HRPconjugated anti-phospho-tyrosine antibody (\#610011; BD Biosciences, Franklin Lakes, NJ) at 1:2500 in blocking solution. The immunoblot was developed with enhanced chemiluminescence substrate (Pierce, Rockford, IL), and the signal was captured with the Kodak Image System
2000R. The membrane was then stripped in Restore Western Blot Stripping Buffer (Pierce), blocked in 3\% milk/5\% BSA/TBST, and incubated with the anti-EphA4R antibody (1:4000) overnight at $4^{\circ} \mathrm{C}$. After rinsing, the membrane was blocked and incubated in an HRP-conjugated antirabbit antibody (1:2000) (Cell Signaling Technology). The immunoblot was developed and imaged as described above.

Electrophysiology. Cultures were placed in a recording chamber and perfused with extracellular saline containing the following (in $\mathrm{mM}$ ): 145 $\mathrm{NaCl}, 10 \mathrm{NaHCO}_{3}, 10$ HEPES (titrated to $\mathrm{pH} 7.4$ ), $2 \mathrm{CaCl}_{2}, 2 \mathrm{MgCl}_{2}$, and Phenol Red ( $1 \mathrm{mg} / \mathrm{L})$. Postsynaptic CA1 pyramidal neurons were voltage clamped at $-75 \mathrm{mV}$ using standard whole-cell recording techniques. NMDA receptor (NMDAR)-mediated EPSCs were evoked using extracellular stimuli $(0.2-0.7 \mathrm{~mA}$ for $100 \mu \mathrm{s})$ delivered in str. radiatum at the border between areas CA3 and CA1 using a $2 \mathrm{M} \Omega$ patch pipette filled with extracellular saline while the cells were voltage clamped at $-50 \mathrm{mV}$. EPSCs were low-pass filtered at $2 \mathrm{kHz}$ and digitized at $10 \mathrm{kHz}$ using an Axopatch 200B amplifier and Clampex 9 software (Molecular Devices, Sunnyvale, CA). Patch pipettes were filled with the following (in $\mathrm{mm}$ ): 130 gluconic acid, $10 \mathrm{KCl}, 1 \mathrm{MgCl}_{2}$, 2 ATP, 10 HEPES, 0.1 EGTA, Alexa 568 (for visual identification of patched neurons), and the solution was titrated to 7.4 with $\mathrm{KOH}$. Recording pipette resistances were between 6.5 and $10 \mathrm{M} \Omega$; recordings in which the access resistance exceeded $30 \mathrm{M} \Omega$ were discarded.

Photolysis. An argon ion laser fitted with UV optics was used to produce a continuous $300 \mathrm{~mW}$ beam of UV light that was then launched into a quartz fiber and directed to the preparation via collimating lenses and a dichroic mirror, as described in detail previously (Bagal et al., 2005). The duration of the laser pulse ( $32 \mathrm{~ms}$ ) was controlled by a mechanical shutter (NM Laser Products, Sunnyvale, CA). An attenuated UV beam was used to target a well isolated dendritic process for focusing the light. Caged glutamate [ $\mathrm{N}$-(6-nitro-7-coumarylmethyl)-L-glutamate; $1 \mathrm{~mm}$ ] was added directly to the bath after the laser was targeted, and recordings were obtained before and after drug application.

Drugs. Human ephrinA3-Fc, ephrinB1-Fc, and ephrinB2-Fc constructs and a control Fc fragment (R\&D Systems, Minneapolis, MN) were suspended in $200 \mu \mathrm{l}$ of sterile-filtered PBS and added directly to the recording chamber. PI-PLC, from Bacillus cereus (Sigma), was suspended in Tris-buffered saline containing BSA at a concentration of $25 \mathrm{U} / \mathrm{ml}$ and added directly to the recording chamber. All other chemicals were obtained from Sigma (St. Louis, MO), except 3-[[(3,4-dichlorophenyl)methyl]amino]propyl(diethoxymethyl)phosphinic acid (CGP52432) (Tocris Cookson, Ballwin, MO).

\section{Results}

\section{Glial processes display rapid morphological dynamics}

Brain slice cultures are well suited for the study of the structurefunction relationships of the synapse, because they offer the advantages of in vitro systems, including excellent optical properties, ease of transfection, and good control of the experimental conditions while preserving much of the organotypic cytoarchitecture of the intact tissue (Gähwiler, 1984; Gähwiler et al., 1997). The hippocampus is an excellent structure, because neurons and glia attain a high degree of morphological maturity after $>14$ DIV (Frotscher and Gähwiler, 1988; McKinney et al., 1999) and because some of the properties of neuronal and glial ephrin signaling have been characterized (Murai et al., 2003; Nishida and Okabe, 2007).

Neurons and glia were transfected biolistically with GFP to allow the morphology of living cells to be studied (Frotscher and Gähwiler, 1988). Glia were readily distinguished from neurons, which have long $(>200 \mu \mathrm{m})$, highly branched axons with beaded varicosities and dendrites bearing large numbers of dendritic spines (McKinney et al., 1999). Glia within the culture, in contrast, had small cell bodies ( $<15 \mu$ m diameter) with numerous thick processes extending in all directions from the cell body for lengths of $\sim 50 \mu \mathrm{m}$ (Fig. 1) (del Rio et al., 1991; Benediktsson et al., 2005). Many more glia than neurons were typically trans- 
fected. The thick main glial processes were studded with fine $(<1 \mu \mathrm{m}$ diameter $)$ protrusions of up to $10 \mu \mathrm{m}$ in length resembling dendritic filopodia. Less frequently, lamellapodia-like processes were also observed. On average, there were $2 \pm 1$ fine filopodial processes per micrometer of glial branch length, having a mean length of $3.5 \pm 2 \mu \mathrm{m}$ (range, $0.2-10.5 \mu \mathrm{m} ; n=59$ filopodia on six cells for both). Evidence is mounting that astrocytic filopodial processes are likely to represent the points of glial-neuronal interaction at and around the synapse (Ventura and Harris, 1999; Cholet et al., 2002; Murai et al., 2003).

Glial cells comprise several distinct cell types with heterogeneous and partially overlapping morphologies (Kimelberg, 2004). Astrocytes in vivo and in hippocampal slice cultures express constitutively high levels of GFAP and have morphologies similar to the cells we labeled (Eng et al., 2000; Benediktsson et al., 2005). We therefore performed GFAP immunohistochemistry on slice cultures that had been transfected $48 \mathrm{~h}$ previously with GFP, using confocal microscopy to establish colocalization. In all cases ( $n=20$ cells) (data not shown), GFP-transfected glial cells were found to be GFAP immunoreactive, protoplasmic astrocytes.

In agreement with recent observations (Benediktsson et al., 2005), we observed two kinds of constitutive morphological changes in astrocytes in time-lapse image sequences lasting 30-60 min. The most common were small changes in the shape of the distal ends of fine filopodial processes (Fig. 2A), resembling the "morphing" seen in dendritic spine heads (Fischer et al., 1998). In addition, some new filopodial processes were extended from glial trunks, and some preexisting processes were retracted. On average, the process extension was equal to the process retraction, so that there was no net change in total process length during these image sequences. Finally, lamellapodial ruffling was also observed during baseline conditions (Fig. 2B), as reported previously (Benediktsson et al., 2005).

\section{Induction of astrocyte process outgrowth by ephrinA3}

Activation of EphARs induces rapid changes in the size and number of dendritic spines on hippocampal pyramidal cells (Murai et al., 2003). We asked whether activation of EphRs would also affect astrocytic processes. We applied protein constructs in which different ephrins have been fused to a human immunoglobulin Fc fragment, resulting in a soluble EphR ligand (Murai et al., 2003). Images of GFP-expressing astrocytes in str. radiatum of area CA1 were collected each minute for a $30 \mathrm{~min}$ baseline period before addition of the ephrin constructs into the recording chamber at $7.6 \mu \mathrm{g} / \mathrm{ml}$. Scale bar, $4 \mu \mathrm{m}$.
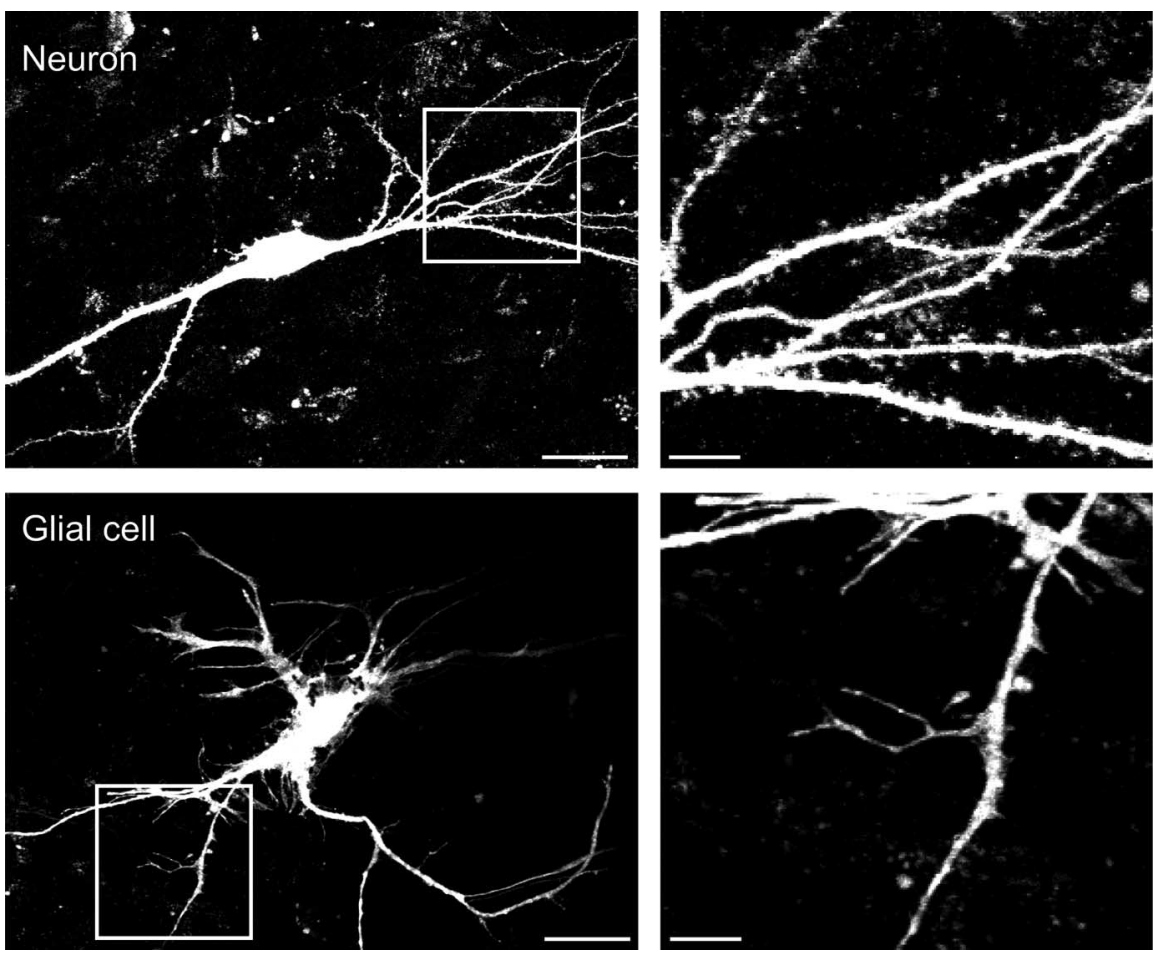

Figure 1. Labeling of astrocytic filopodia with GFP. Low-power (left) and high-power (right) images of a GFP-transfected neuron (top row) and glial cell (bottom row) in a hippocampal slice culture demonstrating the differences in the morphology of
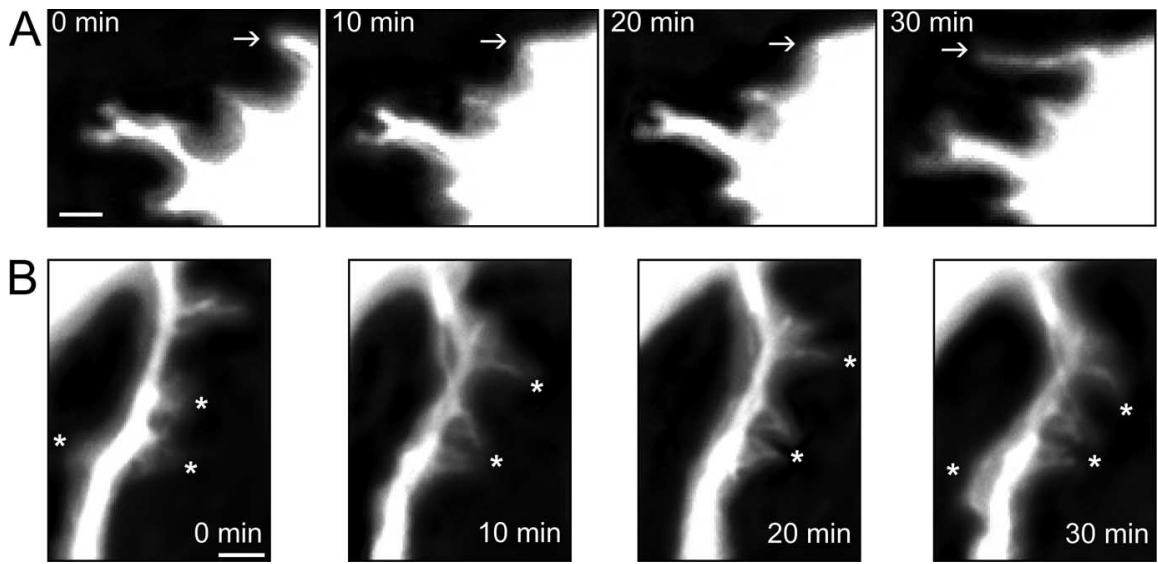

Figure 2. Constitutive morphological dynamics in astrocytes. $\boldsymbol{A}, \boldsymbol{B}$, High-power time-lapse image sequences of filopodia in two GFP-transfected glial cells. Arrows indicate retraction and extension at one site during the baseline activity period. Asterisks indicate ongoing changes in lamellapodia during baseline. Time of image capture is indicated in minutes from start.

Application of the EphAR ligand, ephrinA3-Fc, produced rapid and maintained outgrowth of astrocytic filopodia. The length of many preexisting filopodia more than doubled (average increase over baseline, $139.7 \pm 19 \% ; n=6$ cells) (Fig. $3 A, D)$. EphrinA3-Fc also induced the outgrowth of new filopodia (average increase in the number of processes per unit length of thick process, $48.9 \pm 5 \% ; n=6$ cells) (Fig. $3 B, D$ ). Process growth was initiated within minutes of the addition of the EphAR ligand (Fig. $3 D$ ), and the new and elongated processes persisted for $>60-90$ min. There was no correlation $(r=-0.2 ; n=6$ cells) between mean starting process length and percentage change in process length at $30 \mathrm{~min}$.

This effect was specific for activation of EphARs. First, addi- 

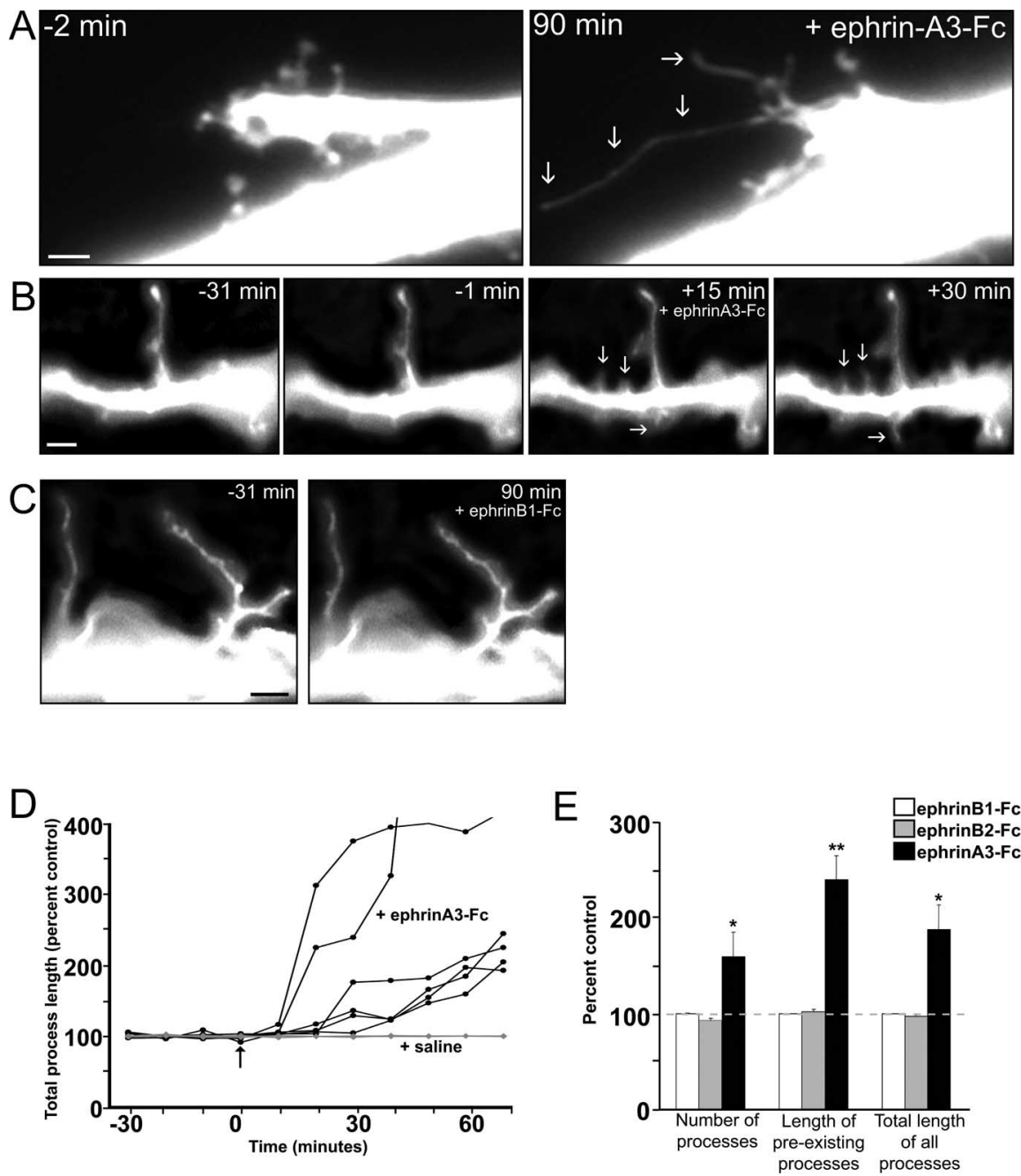

Figure 3. EphrinA3-Fc induces filopodial outgrowth and elongation. $\boldsymbol{A}, \boldsymbol{B}$, Time-lapse image sequences of filopodia in two GFP-transfected astrocytes treated with the ephrinA3-Fc construct. Arrows indicate extensive elongation of filopodia $(\boldsymbol{A})$ and extension of new filopodia at two sites in another cell $(\boldsymbol{B})$. Time of image capture indicated in minutes relative to the addition of ephrinA3-Fc (7.6 $\mu \mathrm{g} / \mathrm{ml})$. Scale bar, $4 \mu \mathrm{m}$. C, Time-lapse image sequences of filopodia in a GFP-transfected astrocyte treated with the ephrinB1-Fc construct. Time of image capture is indicated in minutes relative to the addition of ephrinB1-Fc (7.6 $\mu \mathrm{g} / \mathrm{ml})$. Scale bar, $4 \mu \mathrm{m}$. No changes in filopodia were apparent. $\boldsymbol{D}$, Plot of the time course of the change in total process length, normalized to the mean length during the baseline period, after addition of $7.6 \mu \mathrm{g} / \mathrm{ml}$ ephrinA3-Fc (black; $n=6$ cells) or control saline as a vehicle control (gray; $n=6$ cells). Each line represents the values for one cell, normalized to its own mean pre-ephrin value. Significant difference is indicated at times $>15$ min after application of ephrinA3- $\mathrm{Fc}(p<0.05$; Friedman's ANOVA). E, Summary of ephrinA3-Fc ( $n=6$ cells) and ephrinB1-Fc ( $n=4$ cells), and ephrinB2-Fc ( $n=10$ cells) effects on the number of filopodial per $30 \mu \mathrm{m}$ of astrocytic process, the length of pre-existing filopodia, the total process length, and the average length of astrocytic filopodia. Each cell was normalized to its own mean value during the 30 min baseline period. ${ }^{* *} p<0.01 ;{ }^{*} p<0.05$; ANOVA. Only ephrinA3-Fc promoted filopodial outgrowth and extension.

tion of an equivalent volume of control saline (vehicle) to the recording chamber did not induce any significant net change in astrocytic filopodia (Fig. $3 D$, gray) $(n=5)$. Second, a comparable ligand of EphBRs, ephrinB2-Fc, failed to induce significant changes in astrocytic processes at $7.6 \mu \mathrm{g} / \mathrm{ml}$ (Fig. $3 E$ ) or 11.44 $\mu \mathrm{g} / \mathrm{ml}$ (data not shown). Finally, ephrinB1-Fc $(7.6 \mu \mathrm{g} / \mathrm{ml})$, a ligand that has been shown to bind to some EphARs, had no significant effect on the morphology of astrocytes (Fig. $3 D, E$ ).

We next asked whether endogenous ephrins were able to induce the same morphological changes in astrocytic processes as the exogenous construct. EphrinAs are attached extracellularly to the plasma membrane via GPI anchors (Yamaguchi and Pasquale, 2004). PI-PLC is a temperature-sensitive enzyme that cleaves extracellular GPI links and releases GPI-anchored pro- teins from the plasma membrane (Taguchi et al., 1980). At $37^{\circ} \mathrm{C}$, bath application of PI-PLC produced morphological changes in astrocytic cell processes that were identical to the effects of the ephrinA3-Fc, including an increase in the number of processes and an increase in the length of preexisting processes, resulting in a net increase in total process length (Fig. $4 A, B)$. No process outgrowth was seen when PI-PLC was added at room temperature (Fig. $4 B$ ), although ephrinA3-Fc was fully effective at room temperature (Fig. $3 D, E)$

To determine whether PI-PLC treatment caused activation of EphARs, we assayed the phosphorylation state of EphA4Rs in hippocampal slice cultures using the procedures described by Murai et al. (2003). After immunoprecipitation of EphA4Rs, we detected an increase in the labeling with an anti-phosphotyrosine antibody after application of PI-PLC at $37^{\circ} \mathrm{C}$ but not at room temperature. The degree of activation was comparable with that produced by ephrinA3-Fc application (Fig. 4C)

We conclude that endogenous ephri$\mathrm{nAs}$ are capable of activating EphARs and inducing morphological changes in astrocytic processes.

\section{Astrocytes express Eph receptors}

Many ephrins and EphRs are expressed at high levels in the hippocampus (Liebl et al., 2003; Wang et al., 2003), but little is known about EphR expression in glial cells. We therefore used PCR with a battery of EphR primers (supplemental Fig. $1 B$, available at www.jneurosci.org as supplemental material) to test for glial expression. To study the expression of ephrins and their receptors in astrocytes in situ, we used acutely dissociated astrocytes from the str. radiatum of the rat hippocampus, an area of the hippocampus that is enriched in astrocytes and has few neuronal cell bodies. Acutely dissociated astrocytes display electrophysiological and morphological characteristics that closely resemble those found in acute hippocampal slices (Zhou and Kimelberg, 2001).

mRNAs for multiple EphRs were detected in the acutely isolated cells, including multiple EphARs that can mediate the effects of the ephrinA3-Fc construct (Fig. 5A). To verify the cellular origin of these mRNA transcripts, we used Sytox-green, a highaffinity nucleic acid marker, and an anti-GFAP antibody to stain dissociated cells. We found that 134 of 174 cells were positively labeled with both Sytox-green and the anti-GFAP antibody (four coverslips), suggesting that the mRNA transcripts detected originated primarily from astrocytes. We also examined EphR expression in GFAP-immunoreactive primary glial cell cultures from neocortical tissue. We detected mRNAs for several EphARs (supplemental Fig. 1C, available at www.jneurosci.org as supple- 
A

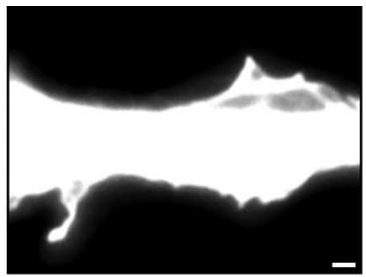

control saline

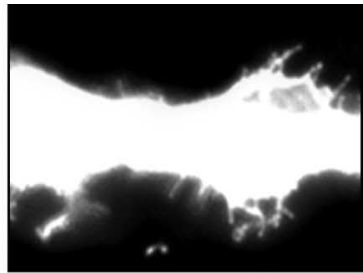

$+\mathrm{PI}-\mathrm{PLC}\left(37^{\circ} \mathrm{C}\right)$
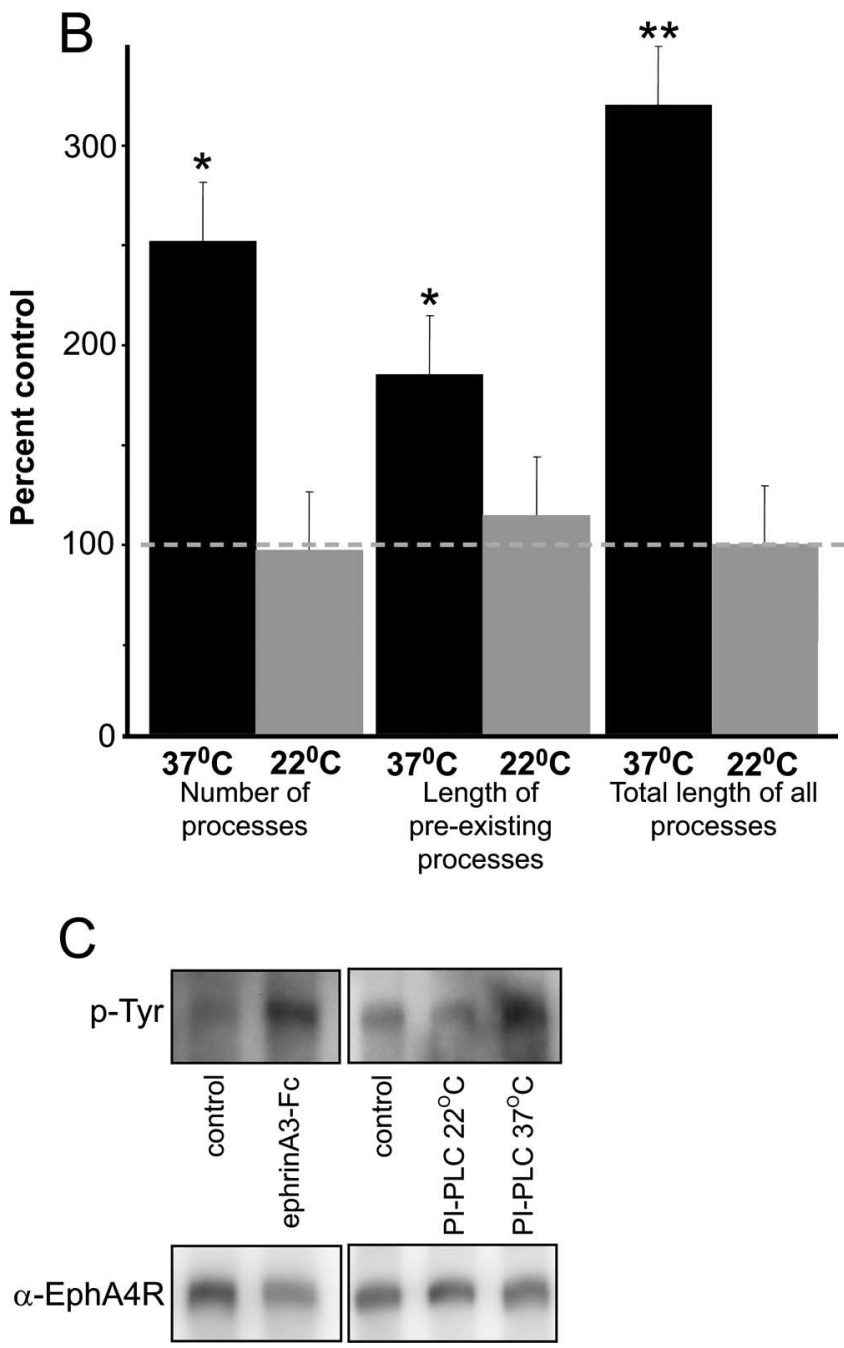

Figure 4. Release of endogenous ephrinAs also promotes filopodia growth. $A$, Images of an astrocytic process $10 \mathrm{~min}$ before and $30 \mathrm{~min}$ after addition of PI-PLC at $37^{\circ} \mathrm{C}$ to cleave GPIanchored endogenous ephrinAs. Note the increase in process number in this example. Scale bar, $4 \mu \mathrm{m}$. B, Summary of PI-PLC effects on the normalized number of filopodia per $25 \mu \mathrm{m}$ of astrocytic process, the length of pre-existing filopodia, the total process length, and the average length of astrocytic filopodia at $37^{\circ} \mathrm{C}\left(n=4\right.$ cells) and $22^{\circ} \mathrm{C}\left(n=4\right.$ cells) $\left({ }^{* *} p<0.01 ;{ }^{*} p<\right.$ 0.05 ; ANOVA). C, EphA4Rs were immunoprecipitated from rat hippocampal slice cultures, and their level of activation was assayed by probing with an anti-phosphotyrosine antibody (top row). Increased phosphotyrosine labeling was seen after application of ephrinA3-Fc and after application of PI-PLC at $37^{\circ} \mathrm{C}$ but not at $22^{\circ} \mathrm{C}$ (bands $\approx 98 \mathrm{kDa}$ ). The membranes were stripped and reprobed with the anti-EphA4R antibody to control for loading (bottom row).

mental material). Our results corroborate previous single-cell PCR data demonstrating that astrocytes in str. radiatum express transcripts for the EphA4R (Murai et al., 2003).

We next used immunocytochemistry to determine whether astrocytes express EphA4Rs. Hippocampal slice cultures were prepared from transgenic mice expressing GFP under the control
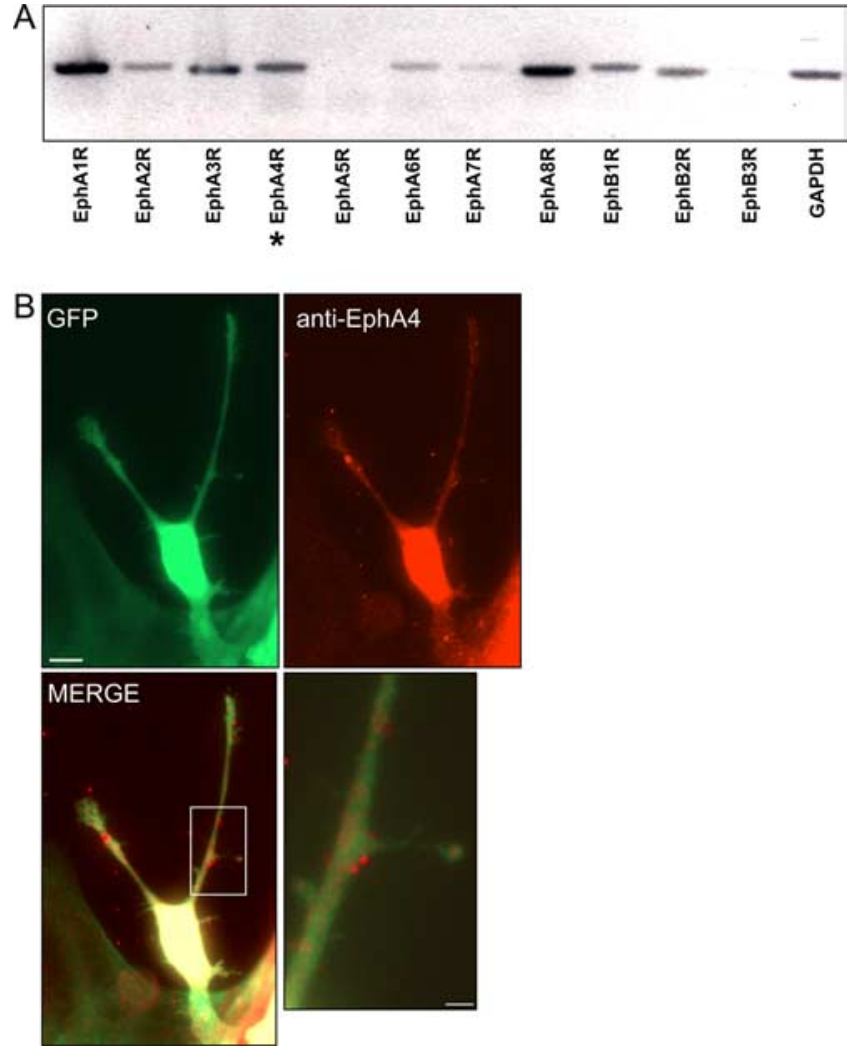

Figure 5. Expression and activation of EphRs in astrocytes. $A$, PCR analysis of EphR expression in adult rat astrocytes acutely dissociated from hippocampal str. radiatum reveals the large number of EphRs they express. $\boldsymbol{B}$, Immunocytochemical staining for anti-EphA4R (red) in hippocampal slice cultures from S100B-GFP mice at high and low magnification reveals that the filopodial processes of hippocampal astrocytes express the EphA4R. Scale bars: $\boldsymbol{B}$, top left, 15 $\mu \mathrm{m}$; bottom right, $4 \mu \mathrm{m}$.

of the S100B promoter (Zuo et al., 2004). S100B is a common marker for glia in a number of brain areas, including hippocampus and cerebral cortex. GFP-expressing cells in these cultures were morphologically similar to biolistically transfected rat astrocytes $(0.52 \pm 0.37$ filopodia/ $\mu \mathrm{m}$ process length; $n=46$ processes; five cells) and were responsive to treatment with ephrins. After the application of ephrinA3-Fc, the total process length increased significantly over baseline ( $38 \pm 5 \% ; p>0.01 ; n=8$ cells) (supplemental Fig. $1 D$, available at www.jneurosci.org as supplemental material). After 2 weeks in vitro, the cultures were fixed and stained with an anti-EphA4 antibody. Filopodial processes of the GFP-expressing astrocytes were labeled with the EphA4 antibody, confirming both the PCR data and the recent observations of Tremblay et al. (2007). Similar results were obtained with cultured cortical astrocytes. We found that $87 \%$ of cells were labeled with the anti-EphA4R antibody (55 of 63; five coverslips) (supplemental Fig. $1 A$, available at www.jneurosci.org as supplemental material). These results suggest that ephrinAs might induce changes in astrocytic morphology through a direct action at glial EphARs.

\section{EphrinA acts directly on glial cell EphARs}

There are two possible sites of action for ephrinAs in the control of astrocyte morphology: directly on glial EphARs or indirectly via neuronal EphARs. The results above demonstrate that astrocytes themselves express several EphARs. EphrinAs might thus act directly by activating astrocytic EphARs and inducing a change in morphology. Alternatively, Murai et al. (2003) have 

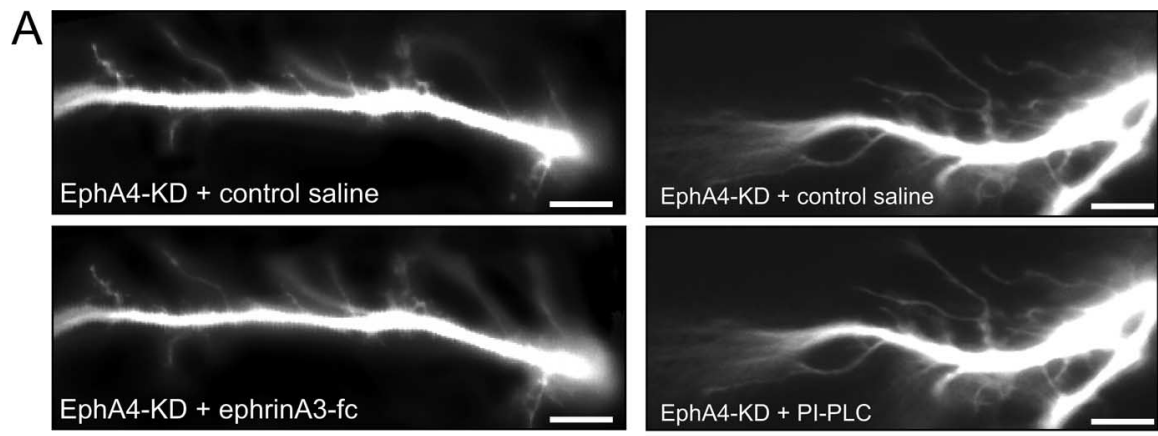

\section{$B$}

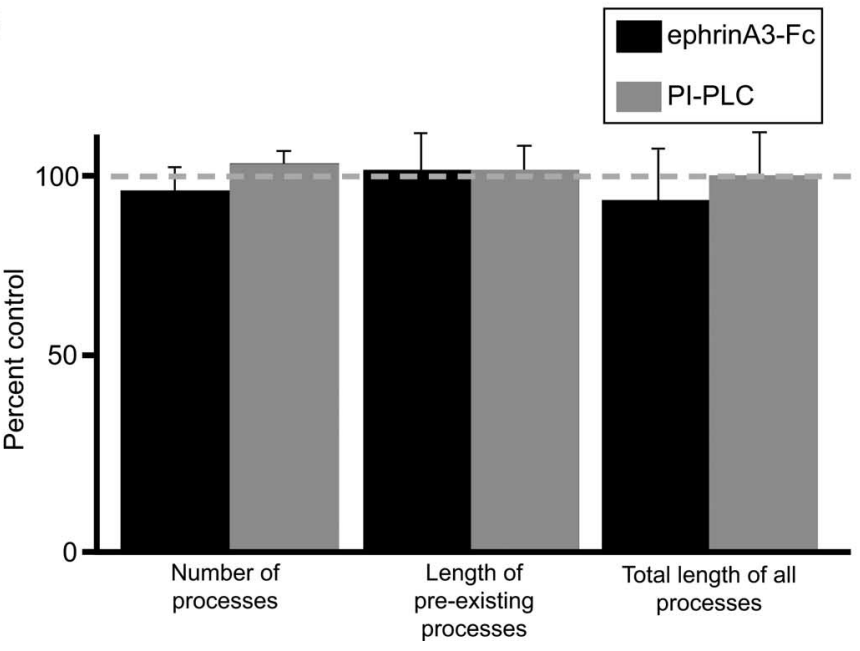

Figure 6. EphrinA3-Fc- and PI-PLC-induced outgrowth is blocked in astrocytes expressing a dominant-negative EphAR. $\boldsymbol{A}$ Images of filopodial processes $5 \mathrm{~min}$ before and $45 \mathrm{~min}$ after addition of ephrinA3-Fc (left column, 7.6 $\mu \mathrm{g} / \mathrm{ml}$ ) or PI-PLC (right column) at $37^{\circ} \mathrm{C}$ in astrocytes transfected with a dominant-negative kinase-dead EphA4 construct. Scale bar, $5 \mu \mathrm{m}$. $\boldsymbol{B}$, Summary of the effects of addition of the ephrinA3-Fc construct or PI-PLC on the normalized number of filopodia per $25 \mu \mathrm{m}$ of astrocytic process, the length of pre-existing filopodia, the total process length, and the average length of astrocytic filopodia, measured 30 min after addition of the ephrinA3-Fc construct and normalized to mean pre-ephrin values. All values are not significantly different (ANOVA).

demonstrated that EphA4Rs are localized on dendritic spines and that their activation causes them to shrink. The extension of astrocytic processes in this case could therefore represent an expansion of astrocytic volume to compensate for the reduction in neuronal volume in the synapse. It is also possible that activation of neuronal EphARs causes them to secrete some unknown factor that induces the outgrowth of astrocytic processes indirectly.

To distinguish these hypotheses, we coexpressed cDNAs for GFP and a kinase-dead EphA4R construct in astrocytes (Fig. 6A). The kinase-dead EphA4R multimerizes with endogenous EphA4Rs and thereby acts in a dominant-negative manner ( $\mathrm{Mu}-$ rai et al., 2003). We then visualized the morphology of GFPexpressing transfected astrocytes in organotypic hippocampal slice cultures $48 \mathrm{~h}$ after transfection. Filopodia were significantly longer than in astrocytes transfected with GFP alone (mean, $6.73 \pm 0.38 \mu \mathrm{m}$; range, $2.4-15.1 \mu \mathrm{m} ; n=91$ filopodia; five cells; $p<0.05, t$ test). These filopodia displayed normal constitutive morphing in control saline. Unlike astrocytes transfected with GFP alone, however, application of ephrinA3-Fc produced no significant change in the number (mean, $0.47 \pm 0.05$ per $\mu \mathrm{m}$ process length; five cells) or length of astrocytic processes compared with controls. (Fig. 6B). We next asked whether PI-PLCinduced outgrowth of filopodia from astrocytes was mediated by EphARs by applying PI-PLC at $37^{\circ} \mathrm{C}$ to astrocytes expressing both GFP and the kinase-dead EphA4R (Fig. 6A). Application of PI$\mathrm{PLC}$ in this case induced no significant increase in filopodial processes, suggesting that direct EphAR activation is required for mediating this effect (Fig. 6B). The actions of PI-PLC must therefore be induced by release of ephrinAs, rather than some other GPIanchored proteins. We conclude that ephrinA3-Fc application induces morphological changes in astrocytes by stimulating glial EphA4Rs directly.

\section{EphrinA modulation of glial glutamate release}

The synapse is ensheathed by astrocytic processes, and astrocytes exert numerous influences over the function of presynaptic and postsynaptic neuronal elements of the synapse. For example, astrocytes release glutamate spontaneously, which activates extrasynaptic NMDA receptors to produce spontaneous SICs in neurons (Fellin et al., 2004). We therefore asked whether the morphological effects of ephrinAs on glial cells were accompanied by electrophysiological changes in glial-neuronal interactions by testing the effects of EphAR activation on SICs in CA1 pyramidal cells.

We first compared SICs in slice cultures with reported properties of SICs in ex vivo hippocampal slices. SICs are NMDARdependent currents that contain no fast AMPA receptor (AMPAR)-mediated component and are not abolished by blocking neuronal transmitter release with TTX or tetanus toxin (Angulo et al., 2004; Fellin et al., 2004). The release of glutamate from astrocytes is mediated by the elevation of intracellular calcium in astrocytes (Parri et al., 2001) and can be promoted by activation of astrocytic mGluR 5 type metabotropic glutamate receptors with the selective agonist (S)3,5-dihydroxyphenylglycine (DHPG) (D'Ascenzo et al., 2007). Whole-cell voltage-clamp recordings were made from CA1 pyramidal cells in organotypic hippocampal slice cultures. Cultures were bathed in $\mathrm{Mg}^{2+}$-free saline containing the following: bicuculline (40 $\mu \mathrm{M})$, CGP52432 $(2 \mu \mathrm{M})$, TTX $(1 \mu \mathrm{M})$, and DNQX (20 $\mu \mathrm{M})$ to block $\mathrm{GABA}_{\mathrm{A}} \mathrm{Rs}, \mathrm{GABA}_{\mathrm{B}} \mathrm{Rs}$, action potentials, and AMPARs. As in acute hippocampal slices (Fellin et al., 2004; D'Ascenzo et al., 2007), DHPG-evoked SICs in organotypic hippocampal slice cultures occurred at low frequency $(1.3 \pm 0.3$ SICs/min; $n=190$ events), had a slow rise time (91.5 $\pm 3.3 \mathrm{~ms})$, prolonged decay times $(476.0 \pm 21.7 \mathrm{~ms})$, and relatively large amplitudes ( $-93.6 \pm 3.4 \mathrm{pA}$ ) (supplemental Fig. $1 F-H$, available at www.jneurosci.org as supplemental material). SICs in hippocampal slice cultures were mostly eliminated by application of $40 \mu \mathrm{M}$ D-AP-5 ( $n=4$ cells; $p>0.05, t$ test) (supplemental Fig. $2 D$, available at www.jneurosci.org as supplemental material), as in ex vivo slices.

We then asked whether the application of ephrinA3-Fc would affect the number of SICs recorded from CA1 pyramidal neurons in response to stimulation with $3 \mu \mathrm{M}$ DHPG. After recording SICs for a $10 \mathrm{~min}$ baseline period, ephrinA3-Fc was bath-applied at $7.6 \mu \mathrm{g} / \mathrm{ml}$, as in the experiments above, and SICs were recorded for $50 \mathrm{~min}(n=6)$. After the application of ephrinA3-Fc, the 
frequency of SICs was decreased significantly (Fig. $7 A, B$ ). In contrast, SIC frequency was not changed significantly during $1 \mathrm{~h}$ of recording in cells maintained in control saline or in cells exposed to a control Fc construct (Fig. $7 B, C$ ).

Glia also express high levels of the glutamate transporter excitatory amino acid transporter 2 (or GLT-1) and thus play an important role in preventing glutamate from spreading from its site of release to adjacent synapses (Tanaka et al., 1997; Huang and Bergles, 2004). Does the ephrinA-induced decrease in SIC frequency reflect decreased neuronal sensitivity to astrocyte glutamate or decreased astrocyte glutamate release? To distinguish these possibilities, we first recorded NMDA receptor-mediated EPSCs from CA1 cells in response to stimulation of Schaffer collateral afferents. NMDAEPSCs were recorded with cells voltage clamped at $-50 \mathrm{mV}$ in the presence of DNQX before and after the application of ephrinA3-Fc (Fig. 8A). Application of ephrinA3-Fc for $50 \mathrm{~min}$ had no effect on either the amplitude or decay time constant of these isolated NMDAR-mediated synaptic currents $(n=7)$ (Fig. $8 B)$. We conclude that ephrinAs do not affect the sensitivity of synaptic NMDARs in CA1 neurons.

Unlike conventional synaptic currents, glutamate released by astrocytes acts primarily on extrasynaptic NMDARs (Fellin et al., 2004). We therefore tested the effect of ephrinA3-Fc on extrasynaptic NMDARs by using microphotolysis of caged glutamate (Bagal et al., 2005) to evoke NMDAR-dependent responses. To activate primarily extrasynaptic NMDARs, the UV light was targeted to dendritic shaft sites that were $>1 \mu \mathrm{m}$ away from any dendritic spines (Fig. $8 B$ ). The resulting photolysis-evoked responses (phEPSCs) had amplitudes and kinetics that were similar to synaptic EPSCs and SICs (Fig. 8A). Application of ephrinA3-Fc had no effect on phEPSC amplitude or decay time constant $(n=5)$ (Fig. $8 C$ ). We therefore conclude that the ephrinA3-Fc-induced decrease in SIC frequency is not attributable to a decrease in neuronal sensitivity to glutamate, but rather must be a result of decreased astrocytic release of glutamate.

\section{EphrinAs modulate spontaneous intracellular $\left[\mathrm{Ca}^{2+}\right]$ oscillations in astrocytes}

How might activation of glial EphARs decrease spontaneous glutamate release? Spontaneous oscillations in the concentration of intracellular $\mathrm{Ca}^{2+}$ in astrocytes have been studied extensively and have been implicated in both morphological and physiological changes in astrocytes (Montana et al., 2006), including spontaneous glutamate release (Fiacco and McCarthy, 2006) and the generation of SICs (D’Ascenzo et al., 2007). Spontaneous astro-
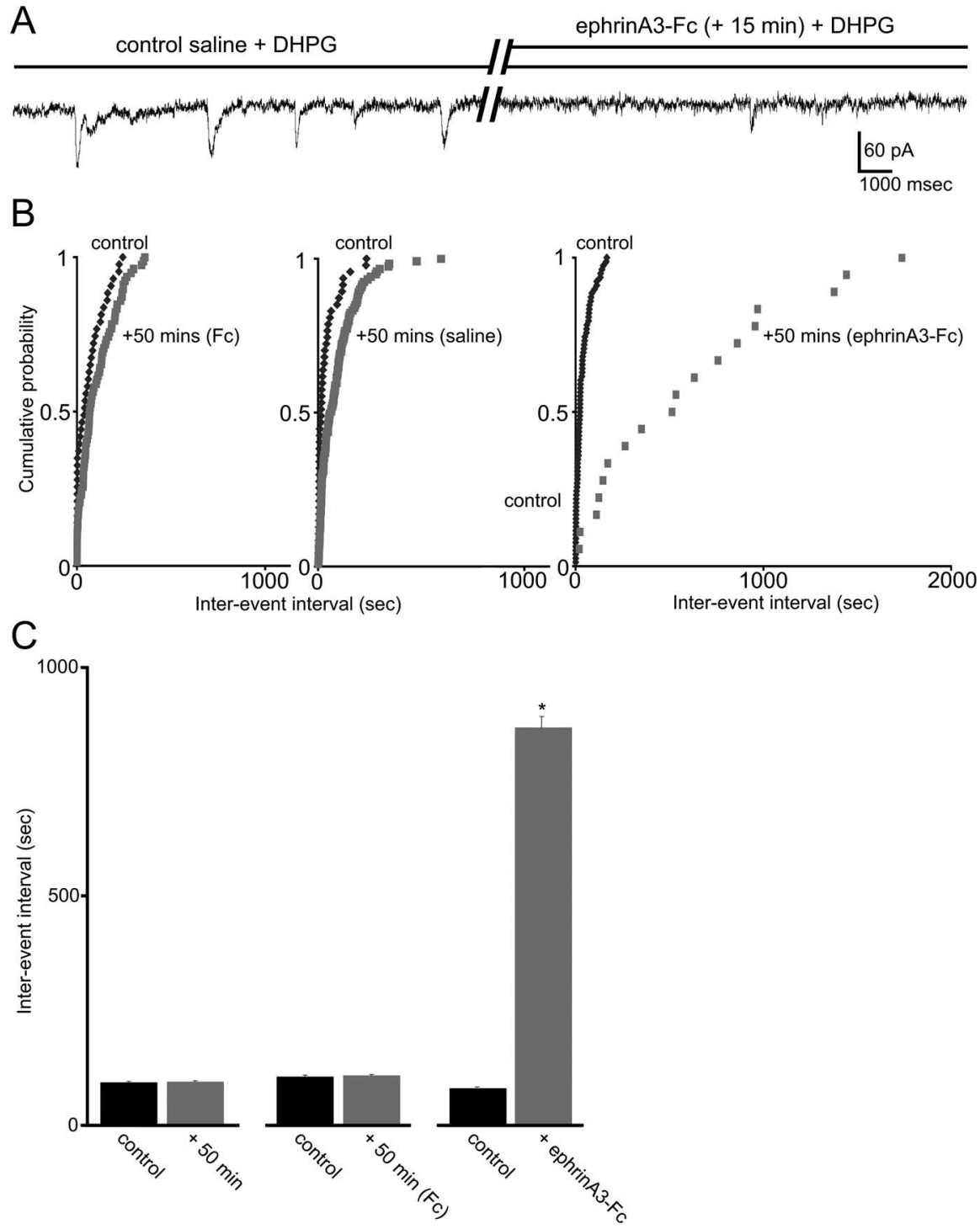

Figure 7. EphrinA inhibits glial release of glutamate. A, DHPG-evoked SICs in a CA1 pyramidal cell before and 15 min after application of ephrinA3-Fc $(7.6 \mu \mathrm{g} / \mathrm{ml})$, recorded under whole-cell voltage clamp $(-50 \mathrm{mV})$ in the presence of $\mathrm{Mg}^{2+}$-free saline of any construct (middle graph; 5 cells). C, Mean interevent intervals for astrocytes in $\boldsymbol{B}$ are plotted for control saline, control- $\mathrm{Fc}$, and ephrinA3-Fc. Only ephrinA3-Fc produced a significant change in the distribution (7 of 7 cells; Komolgorov-Smirnov test; ${ }^{*} p<0.05$ ).

cytic $\mathrm{Ca}^{2+}$ oscillations can occur independently of neuronal activation, but their kinetics can be modulated by various substances (Bowser and Khakh, 2007).

To test the effect of ephrinAs on spontaneous astrocyte calcium oscillations, we loaded primary mouse hippocampal neuron-glia cocultures (7 DIV) with the membrane permeable fluorescent calcium indicator fluo-4 AM $(2 \mu \mathrm{M})$ and applied $6 \mu \mathrm{M}$ DHPG to mimic the conditions of the experiments above. Oscillations of fluo-4 emission of $40-80 \%(\Delta F / F)$ were readily apparent at $\sim 3 \mathrm{~Hz}$ and were loosely coupled between nearby cells $(n=$ 71; four coverslips) (Fig. 9A,B). Application of ephrinA3-Fc produced a large decrease in the frequency of the spontaneous $\left[\mathrm{Ca}^{2+}\right]$ oscillations ( $n=84$ cells; four coverslips) and a modest decrease in the duration of individual $\mathrm{Ca}^{2+}$ transients (control, $3.77 \pm 1.09$ s/event; ephrinA3-Fc, $4.14 \pm 0.97$ s/event; $n=945$ events; 20 cells) (Fig. $9 A, B$ ), without significantly affecting their 
A

EPSC
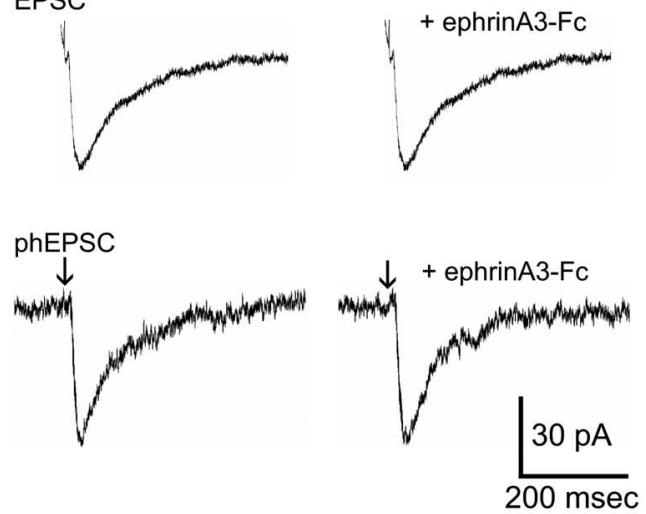

C
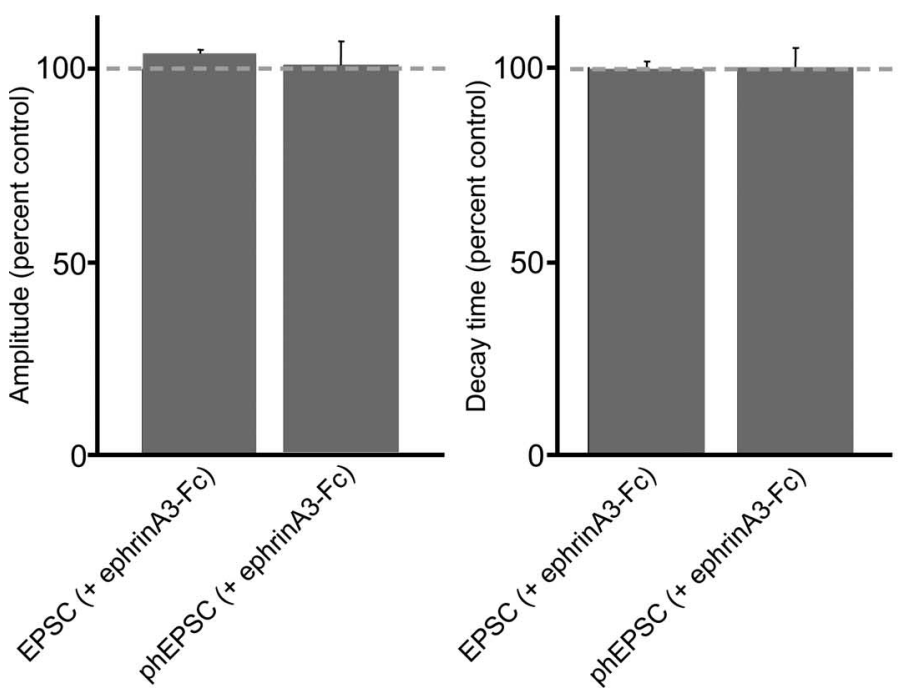

Figure 8. EphrinA does not affect neuronal NMDAR sensitivity. $\boldsymbol{A}$, Representative NMDAR-mediated responses are shown before and $50 \mathrm{~min}$ after the application of ephrinA3-Fc $(7.6 \mu \mathrm{g} / \mathrm{ml})$. Responses were elicited with Schaffer collateral stimulation (top traces) in control saline with the cell voltage clamped at $-50 \mathrm{mV}$ or with photolysis of caged glutamate at extrasynaptic dendritic sites (bottom traces) in $\mathrm{Mg}^{2+}$-free saline with the cell voltage clamped at $-70 \mathrm{mV}$. All salines contained DNQX (40 $\left.\mu \mathrm{M}\right)$, bicuculline methobromide (40 $\mu \mathrm{M})$, and CGP52432 (2 $\mu \mathrm{M})$. B, Images of dye-filled CA1 cell dendrites used for uncaging experiments at high and low magnification. Scale bar, $4 \mu \mathrm{m}$. The UV spot used for uncaging was targeted to dendritic shaft sites at distances of $>1 \mu \mathrm{m}$ from the base of dendritic spines to ensure that primarily extrasynaptic NMDARs were stimulated. $\boldsymbol{C}$, Summary graphs indicating that application of ephrinA3-Fc had no effect on the amplitude or decay time of NMDA receptormediated currents elicited with either synaptic stimulation or photolysis of caged glutamate at extrasynaptic sites.

amplitude (Fig. 9C). In contrast, no change in spontaneous $\left[\mathrm{Ca}^{2+}\right]$ oscillation frequency was seen after the application of a control Fc construct (Fig. 9B). We conclude that ephrinAs can affect spontaneous oscillations in astrocytic intracellular $\left[\mathrm{Ca}^{2+}\right]$ and suggest that this action may account for their ability to inhibit spontaneous glutamate release.

\section{Discussion}

Ongoing morphological changes in astrocytic processes have been reported recently (Hirrlinger et al., 2004; Benediktsson et al., 2005), a finding that we confirm. We have demonstrated that astrocytes in rat hippocampal slice cultures respond to activation of their EphARs by increasing the length and number of their fine filopodial processes. Our results reveal that dynamic changes in astrocytic morphology can also be regulated by changes in EphAR activation. In conjunction, we also found that ephrins also regulate functional astrocyte-neuron communication by inhibiting intracellular $\left[\mathrm{Ca}^{2+}\right]$ oscillations in astrocytes and their release of glutamate.

It is noteworthy that both the induction of astrocyte process outgrowth and the increase in EphA4R phosphorylation produced by ephrinA3-Fc application were mimicked by releasing endogenous ephrinAs with enzymatic cleavage of their GPI anchors. The actions of both the exogenous and endogenous ligands were dependent on activation of glial EphARs. EphRs bind monomeric ephrin ligands with high affinity (Davis et al., 1994). Formation of these ligand-receptor heterodimers precedes the assembly of tetrameric complexes via lower affinity binding sites (Davis et al., 1994). Our results demonstrate that endogenous ephrins can activate EphAR signaling in astrocytes in the absence of cell-cell contact, perhaps because multimerization of the ligandreceptor complexes occurs after the binding of ligand monomers released by PIPLC with their receptors (Stein et al., 1998). These data represent the first description, to our knowledge, of a noncell contact-mediated effect of endogenous ephrins.

There is now strong evidence that adult astrocytes in situ and in culture express several Eph receptors. We used PCR and a battery of EphR primers to demonstrate that glial cells, both acutely isolated from adult rat hippocampus and cultured from mouse embryos, express multiple EphR transcripts. Differences in the size of some PCR products suggests the differential expression of EphR splice variants in the two types of glial cells. These data thus confirm the observation of EphA4R in astrocytes in the str. radiatum of the mouse hippocampus obtained with single-cell PCR (Murai et al., 2003). Expression of numerous EphR mRNAs at low levels in glial cells of the str. radiatum of the mouse hippocampus is also apparent in the high resolution in situ hybridization data compiled by the Allen Brain Institute (Lein et al., 2007). Our immunocytochemical observations and recent electron microscopy data (Tremblay et al., 2007) demonstrate that EphA4Rs are present on fine filopodial processes of hippocampal astrocytes. We conclude that these astrocytic EphARs mediate the effects of endogenous and exogenous ephrinAs on process outgrowth, because ephrinAs exert no effects on glia cells transfected with a dominant-negative kinase-dead EphA4R construct. There is clear evidence for the existence of EphA4Rs on dendritic spines (Murai et al., 2003). It is possible that changes in astro- 
cyte morphology may also occur indirectly through activation of dendritic spine EphARs, resulting in changes in spine morphology (Haber et al., 2006; Nishida and Okabe, 2007) and secondary remodeling of astrocyte processes.

\section{Synapse wrapping}

Differential activation of EphA and EphB receptors by ephrins represents a key axonal guidance cue in the formation of the retinotopic map in the superior colliculus (O'Leary and McLaughlin, 2005). EphARs are also critical in establishing topographically organized hippocampal-septal projections (Yue et al., 2002). There is considerable evidence that activation of EphB receptors regulates the structure and function of excitatory synapses in the hippocampus (Dalva et al., 2000; Grunwald et al., 2001; Penzes et al., 2003). The present findings, together with those of Murai et al. (2003), indicate that another important function of ephrin signaling is the dynamic regulation of synaptic microstructure. Synaptic contacts between presynaptic nerve terminals and postsynaptic dendritic spines are ensheathed by fine astrocytic processes. Activation of EphARs thus causes the coordinated retraction of dendritic spines and extension of astrocytic filopodia. The time course of these events appears roughly similar, beginning within minutes of ephrin application. The opposing direction of the change in process length suggests that EphARs in the two cell types are coupled to different downstream signaling cascades, which induce different rearrangements of the cytoskeleton. Retraction of dendritic spines, under other conditions, is correlated with a decrease in the frequency of miniature AMPAR-mediated synaptic currents (Tyler and Pozzo-Miller, 2003), suggesting an important functional consequence of neuronal EphAR-mediated spine retraction.

Glia express ephrinA3 (Murai et al., 2003) and could therefore be the source of the ephrinAs activating neuronal EphARs. Neither the source nor the endogenous ligand activating astrocytic EphARs in situ is known, although many ephrinA ligands are expressed in the hippocampus (Taguchi et al., 1980; Murai et al., 2003). Physical contact between glia and neuronal dendrites during synaptogenesis has recently been shown to affect the dynamics and maturation of developing dendritic spines (Nishida and Okabe, 2007). It would be of interest to determine whether ephrins play any role in this event. There is also emerging evidence that both ephrinA and EphAR expression is increased after various CNS injuries (Willson et al., 2002; Sobel, 2005). EphrinA-EphAR signaling may
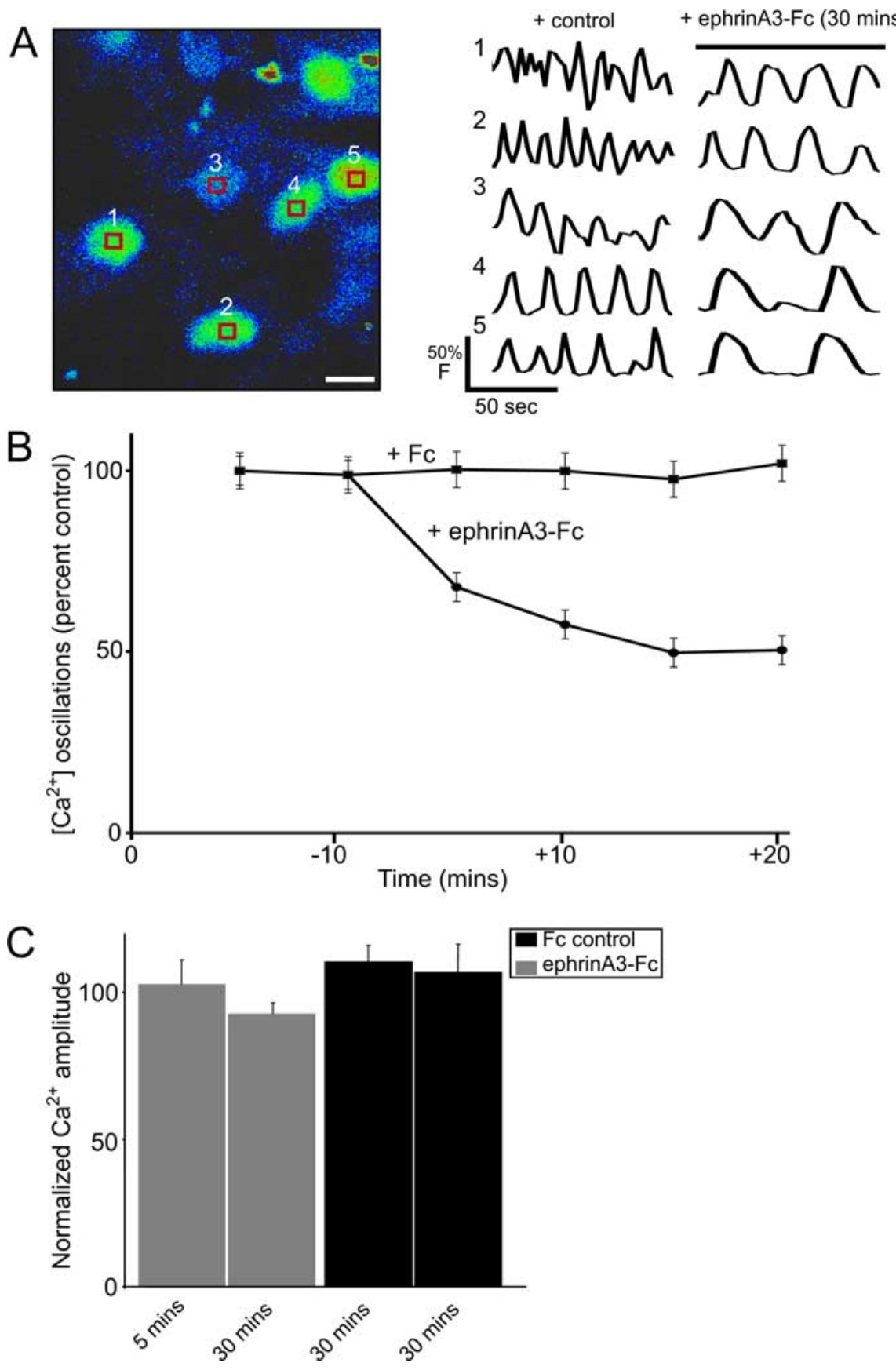

Figure 9. EphrinAs inhibit spontaneous calcium oscillations in astrocytes. A, Image of peak fluo-4 emission from cultured primary mouse astrocytes indicating regions of interest used for measurements of intracellular $\left[\mathrm{Ca}^{2+}\right]$ oscillations shown at right before and $30 \mathrm{~min}$ after application of ephrinA3-Fc $(7.6 \mu \mathrm{g} / \mathrm{ml})$. Scale bar, $10 \mu \mathrm{m}$. B, Normalized frequency of intracellular $\left[\mathrm{Ca}^{2+}\right]$ oscillations in astrocytes at various times after treatment with ephrinA3-Fc (circles; $n=84$ cells) or control $\mathrm{Fc}$ (squares; $n=71$ cells). Significant difference is indicated at times after $10 \mathrm{~min}(p<0.05$, Friedman's ANOVA). C, We observed no significant difference in the amplitude of $\mathrm{Ca}^{2+}$ oscillations in astrocytes treated with either ephrinA3-Fc or Fc-controls, compared with their starting amplitude (Friedman's ANOVA, $p>0.05$ ).

therefore be important in the activation and mobilization of astrocytes after injury.

\section{Biochemical consequences of EphAR activation}

Although EphARs are expressed at high levels in adult hippocampus, they display little or no evidence of constitutive activation (Murai et al., 2003), suggesting that the EphAR may play a role in time-specific morphological changes that occur during activitydependent forms of plasticity requiring rapid restructuring of the 
actin cytoskeleton, such as long-term potentiation. A number of interesting possibilities exist for explaining the downstream cascade leading to changes in astrocyte morphology. Numerous studies have shown that EphRs trigger cytoskeletal changes via stimulation of guanine nucleotide exchange factors, such as ephexin (Shamah et al., 2001), for the small GTPases. Rho GTPase, for example, is involved in regulating the organization and assembly of the actin cytoskeleton in astrocytes (Hall, 1998; Bonhoeffer and Yuste, 2002). Our results suggest that the inhibition of spontaneous glutamate release from glia by ephrinAs is mediated by a decrease in the frequency, and increase in the duration, of spontaneous calcium oscillations in glia. A recent study by Bowser and Khakh (2007) may suggest how ephrinA-induced changes in $\mathrm{Ca}^{2+}$-transient duration may also contribute to the decrease in SIC frequency. Changes in the duration of intracellular $\mathrm{Ca}^{2+}$ transients may affect the mode of vesicle exocytosis from the astrocyte (full vesicle fusion vs kiss-and-run). It should be noted, however, that Fiacco et al. (2007) have suggested recently that $\mathrm{Ca}^{2+}$ elevation is not obligatorily coupled to astrocytic glutamate release. Nevertheless, it will be of considerable interest to determine the biochemical pathway mediating these effects, because ephrinA modulation of spontaneous calcium oscillations may mediate multiple effects on astrocyte-neuron crosstalk (Perea and Araque, 2007). For example, glial release of ATP (Pascual et al., 2005), an important regulator of astrocyte calcium wave propagation (Guthrie et al., 1999), may also be affected by EphAR activation.

\section{Functional consequences}

One important role of astrocytes at the synapse is to limit the spillover of glutamate. EphAR activation produced no detectable change in the decay rate of NMDAR-mediated responses evoked with either synaptic stimulation or glutamate uncaging. These findings indicate that the promotion of glial process outgrowth does not affect monosynaptic NMDAR-mediated transmission. Nevertheless, the concomitant changes in astrocyte morphology and spontaneous glutamate release induced by ephrinA-EphAR signaling can be predicted to ultimately decrease crosstalk between synapses and thus limit the cooperative activation of NMDARs in adjacent synapses. Because glia also play an important role in the clearance of extracellular $\mathrm{K}^{+}$away from regions of high activity or compromised metabolism, ephrinA-EphAR triggered alterations in synaptic wrapping may help to limit potentially excitotoxic levels of depolarization and transmitter release (Kofuji and Newman, 2004; Simard and Nedergaard, 2004). Although the physiological conditions that promote ephrinAEphAR signaling in situ are not fully characterized, our observations and those of others (Murai et al., 2003) reveal that this signaling pathway has a unique ability to regulate the structure and function of all elements of the tripartite synapse in a coordinated manner.

\section{References}

Angulo MC, Kozlov AS, Charpak S, Audinat E (2004) Glutamate released from glial cells synchronizes neuronal activity in the hippocampus. J Neurosci 24:6920-6927.

Araque A, Carmignoto G, Haydon PG (2001) Dynamic signaling between astrocytes and neurons. Annu Rev Physiol 63:795-813.

Bagal AA, Kao JP, Tang CM, Thompson SM (2005) Long-term potentiation of exogenous glutamate responses at single dendritic spines. Proc Natl Acad Sci USA 102:14434-14439.

Benediktsson AM, Schachtele SJ, Green SH, Dailey ME (2005) Ballistic labeling and dynamic imaging of astrocytes in organotypic hippocampal slice cultures. J Neurosci Methods 1:41-53.
Bonhoeffer T, Yuste R (2002) Spine motility: phenomenology, mechanisms and function. Neuron 35:1019-1027.

Bowser DN, Khakh BS (2007) Two forms of single-vesicle astrocyte exocytosis imaged with total internal reflection fluorescence microscopy. Proc Natl Acad Sci USA 104:4212-4217.

Cholet N, Pellerin L, Magistretti PJ, Hamel E (2002) Similar perisynaptic glial localization for the $\mathrm{Na}^{+}, \mathrm{K}^{+}$-ATPase alpha2 subunit and the glutamate transporters GLAST and GLT-1 in the rat somatosensory cortex. Cereb Cortex 5:515-525.

Dalva MB, Takasu MA, Lin MZ, Shamah SM, Hu L, Gale NW, Greenberg ME (2000) EphB receptors interact with NMDA receptors and regulate excitatory synapse formation. Cell 10:945-956.

D’Ascenzo M, Fellin T, Terunuma M, Revilla-Sanchez R, Meaney DF, Auberson YP, Moss SJ, Haydon PG (2007) mGluR5 stimulates gliotransmission in the nucleus accumbens. Proc Natl Acad Sci USA 104:1995-2000.

Davis S, Gale NW, Aldrich TH, Maisonpierre PC, Lhotak V, Pawson T, Goldfarb M, Yancopoulos GD (1994) Ligands for EPH-related receptor tyrosine kinases that require membrane attachment or clustering for activity. Science 266:816-819.

del Rio JA, Heimrich B, Soriano E, Schwegler H, Frotscher M (1991) Proliferation and differentiation of glial fibrillary acidic proteinimmunoreactive glial cells in organotypic slice cultures of rat hippocampus. J Neurosci 43:335-347.

Eng LF, Ghirnikar RS, Lee YL (2000) Glial fibrillary acidic protein: GFAPthirty-one years (1969-2000). Neurochem Res 25:1439-1451.

Fellin T, Pascual O, Gobbo S, Pozzan T, Haydon PG, Carmignoto G (2004) Neuronal synchrony mediated by astrocytic glutamate through activation of extrasynaptic NMDA receptors. Neuron 43:729-743.

Fiacco TA, McCarthy KD (2006) Astrocyte calcium elevations: properties, propagation, and effects on brain signaling. Glia 54:676-690.

Fiacco TA, Agulhon C, Taves SR, Petravicz J, Casper KB, Dong X, Chen J, McCarthy KD (2007) Selective stimulation of astrocyte calcium in situ does not affect neuronal excitatory synaptic activity. Neuron 54:611-626.

Fischer M, Kaech S, Knutti D, Matus A (1998) Rapid actin-based plasticity in dendritic spines. Neuron 5:847-854.

Flanagan JG, Vanderhaeghen P (1998) The ephrins and Eph receptors in neural development. Annu Rev Neurosci 21:309-345.

Frotscher M, Gähwiler BH (1988) Synaptic organization of intracellularly stained CA3 pyramidal neurons in slice cultures of rat hippocampus. Neuroscience 2:541-551.

Gähwiler BH (1984) Development of the hippocampus in vitro: cell types, synapses, and receptors. Neuroscience 11:751-760.

Gähwiler BH, Capogna M, Debanne D, McKinney RA, Thompson SM (1997) Organotypic slice cultures: a technique has come of age. Trends Neurosci 20:471-477.

Gähwiler BH, Thompson SM, McKinney RA, Debanne D, Robertson RT (1998) Organotypic slice cultures of neural tissue. In: Culturing nerve cells, Ed 2 (Banker G, Goslin K, eds), pp 379-411. Cambridge, MA: MIT.

Garcia-Segura LM, Luquin S, Parducz A, Naftolin F (1994) Gonadal hormone regulation of glial fibrillary acidic protein immunoreactivity and glial ultrastructure in the rat neuroendocrine hypothalamus. Glia 10:59-69.

Grunwald IC, Korte M, Wolfer D, Wilkinson GA, Unsicker K, Lipp HP, Bonhoeffer T, Klein R (2001) Kinase-independent requirement of EphB2 receptors in hippocampal synaptic plasticity. Neuron 32:1027-1040.

Guthrie PB, Knappenberger J, Segal M, Bennett MV, Charles AC, Kater SB (1999) ATP released from astrocytes mediates glial calcium waves. J Neurosci 19:520-528.

Haber M, Zhou L, Murai KK (2006) Cooperative astrocyte and dendritic spine dynamics at hippocampal excitatory synapses. J Neurosci 35:8881-8891.

Hall A (1998) RhoGTPases and the actin cytoskeleton. Science 279:509-514.

Haydon PG (2001) GLIA: listening and talking to the synapse. Nat Rev Neurosci 3:185-193.

Hertz L, Zielke HR (2004) Astrocytic control of glutamatergic activity: astrocytes as stars of the show. Trends Neurosci 12:735-743.

Hirrlinger J, Hulsmann S, Kirchhoff F (2004) Astroglial processes show spontaneous motility at active synaptic terminals in situ. Eur J Neurosci 8:2235-2239. 
Huang YH, Bergles DE (2004) Glutamate transporters bring competition to the synapse. Curr Opin Neurobiol 3:346-352.

Kimelberg HK (2004) The problem of astrocyte identity. Neurochem Int 45:191-202.

Kofuji P, Newman EA (2004) Potassium buffering in the central nervous system. Neuroscience 4:1045-1056.

Lein ES, Hawrylycz MJ, Ao N, Ayres M, Bensinger A, Bernard A, Boe AF, Boguski MS, Brockway KS, Byrnes EJ, Chen L, Chen L, Chen TM, Chin MC, Chong J, Crook BE, Czaplinska A, Dang CN, Datta S, Dee NR, et al. (2007) Genome-wide atlas of gene expression in the adult mouse brain. Nature 445:168-176.

Liebl DJ, Morris CJ, Henkemeyer M, Parada LF (2003) mRNA expression of ephrins and Eph receptor tyrosine kinases in the neonatal and adult mouse central nervous system. J Neurosci Res 1:7-22.

Marcaggi P, Attwell D (2004) Role of glial amino acid transporters in synaptic transmission and brain energetics. Glia 3:217-225.

Martone ME, Holash JA, Bayardo A, Pasquale EB, Ellisman MH (1997) Immunolocalization of the receptor tyrosine kinase EphA4 in the adult rat central nervous system. Brain Res 771:238-250.

McAllister AK (2000) Biolistic transfection of neurons. Sci STKE 2000:PL1.

McKinney RA, Capogna M, Dürr R, Gähwiler BH, Thompson SM (1999) Miniature synaptic events maintain dendritic spines via AMPA receptor activation. Nat Neurosci 2:44-49.

Mong JA, Glaser E, McCarthy MM (1999) Gonadal steroids promote glial differentiation and alter neuronal morphology in the developing hypothalamus in a regionally specific manner. J Neurosci 4:1464-1472.

Montana V, Malarkey EB, Verderio C, Matteoli M, Parpura V (2006) Vesicular transmitter release from astrocytes. Glia 54:700-715.

Murai KK, Nguyen LN, Irie F, Yamaguchi Y, Pasquale EB (2003) Control of hippocampal dendritic spine morphology through ephrinA3/EphA4 signaling. Nat Neurosci 2:153-160.

Newman EA (2003) New roles for astrocytes: regulation of synaptic transmission. Trends Neurosci 10:536-542.

Nishida H, Okabe S (2007) Direct astrocytic contacts regulate local maturation of dendritic spines. J Neurosci 27:7851-7861.

O'Leary DD, McLaughlin T (2005) Mechanisms of retinotopic map development: Ephs, ephrins, and spontaneous correlated retinal activity. Prog Brain Res 147:43-65.

Parri HR, Gould TM, Crunelli V (2001) Spontaneous astrocytic $\mathrm{Ca}^{2+}$ oscillations in situ drive NMDAR-mediated neuronal excitation. Nat Neurosci 4:803-812.

Pascual O, Casper KB, Kubera C, Zhang J, Revilla-Sanchez R, Sul JY, Takano H, Moss SJ, McCarthy K, Haydon PG (2005) Astrocytic purinergic signaling coordinates synaptic networks. Science 310:113-116.

Pekny M, Nilsson M (2005) Astrocyte activation and reactive gliosis. Glia 4:427-434.

Penzes P, Beeser A, Chernoff J, Schiller MR, Eipper BA, Mains RE, Huganir RL (2003) Rapid induction of dendritic spine morphogenesis by transsynaptic ephrinB-EphB receptor activation of the Rho-GEF kalirin. Neuron 37:263-274.

Perea G, Araque A (2005) Synaptic regulation of the astrocyte calcium signal. J Neural Transm 1:127-135.
Perea G, Araque A (2007) Astrocytes potentiate transmitter release at single hippocampal synapses. Science 317:1083-1086.

Shamah SM, Lin MZ, Goldberg JL, Estrach S, Sahin M, Hu L, Bazalakova M, Neve RL, Corfas G, Debant A, Greenberg ME (2001) EphARs regulate growth cone dynamics through the novel guanine nucleotide exchange factor ephexin. Cell 105:233-244.

Simard M, Nedergaard M (2004) The neurobiology of glia in the context of water and ion homeostasis. Neuroscience 4:877-896.

Sobel RA (2005) Ephrin A receptors and ligands in lesions and normalappearing white matter in multiple sclerosis. Brain Pathol 15:35-45.

Stein E, Lane AA, Cerretti DP, Schoecklmann HO, Schroff AD, Van Etten RL, Daniel TO (1998) Eph receptors discriminate specific ligand oligomers to determine alternative signaling complexes, attachment, and assembly responses. Genes Dev 12:667-678.

Taguchi R, Asahi Y, Ikezawa H (1980) Purification and properties of phosphatidylinositol-specific phospholipase $\mathrm{C}$ of Bacillus thuringiensis. Biochim Biophys Acta 1:48-57.

Tanaka K, Watase K, Manabe T, Yamada K, Watanabe M, Takahashi K, Iwama H, Nishikawa T, Ichihara N, Kikuchi T, Okuyama S, Kawashima N, Hori S, Takimoto M, Wada K (1997) Epilepsy and exacerbation of brain injury in mice lacking the glutamate transporter GLT-1. Science 276:1699-1702.

Tremblay ME, Riad M, Bouvier D, Murai KK, Pasquale EB, Descarries L, Doucet G (2007) Localization of EphA4 in axon terminals and dendritic spines of adult rat hippocampus. J Comp Neurol 501:691-702.

Tyler WJ, Pozzo-Miller L (2003) Miniature synaptic transmission and BDNF modulate dendritic spine growth and form in rat CA1 neurones. J Physiol (Lond) 553:497-509.

Ventura R, Harris KM (1999) Three-dimensional relationships between hippocampal synapses and astrocytes. J Neurosci 16:6897-6906.

Wang Y, Ying G, Liu X, Zhou C (2003) Semi-quantitative expression analysis of ephrin mRNAs in the deafferented hippocampus. Brain Res Mol Brain Res 120:79-83.

Willson CA, Irizarry-Ramirez M, Gaskins HE, Cruz-Orengo L, Figueroa JD, Whittemore SR, Miranda JD (2002) Upregulation of EphAR expression in the injured adult rat spinal cord. Cell Transplant 11:229-239.

Yamaguchi Y, Pasquale EB (2004) Eph receptors in the adult brain. Curr Opin Neurobiol 3:288-296.

Yue Y, Chen ZY, Gale NW, Blair-Flynn J, Hu TJ, Yue X, Cooper M, Crockett DP, Yancopoulos GD, Tessarollo L, Zhou R (2002) Mistargeting hippocampal axons by expression of a truncated Eph receptor. Proc Natl Acad Sci USA 99:10777-10782.

Zhou M, Kimelberg HK (2001) Freshly isolated hippocampal CA1 astrocytes comprise two populations differing in glutamate transporter and AMPA receptor expression. J Neurosci 21:7901-7908.

Zuo Y, Lubischer JL, Kang H, Tian L, Mikesh M, Marks A, Scofield VL, Maika S, Newman C, Krieg P, Thompson WJ (2004) Fluorescent proteins expressed in mouse transgenic lines mark subsets of glia, neurons, macrophages, and dendritic cells for vital examination. J Neurosci 24:1099911009. 